\title{
The Effects of a Lesion or a Peripheral Nerve Graft on GAP-43 Upregulation in the Adult Rat Brain: An in situ Hybridization and Immunocytochemical Study
}

\author{
E. Vaudano, ${ }^{1}$ G. Campbell, ${ }^{1}$ P. N. Anderson, ${ }^{1}$ A. P. Davies, ${ }^{1}$ C. Woolhead,${ }^{1}$ D. J. Schreyer ${ }^{2}$ and A. R. \\ Lieberman 1 \\ 'Department of Anatomy and Developmental Biology, University College London, London WC 1E 6BT, United \\ Kingdom and 'Department of Physiology, Queen's University, Kingston, Canada K7L 3N6
}

\begin{abstract}
We have sought to determine (1) if thalamic neurons upregulate the growth associated protein GAP-43 as a response to injury, or if a peripheral nerve graft is required to induce, enhance or sustain such a response, and (2) if thalamic neurons with different regenerative potentials also display different GAP-43 responses. Levels of GAP-43 protein (detected by LM and EM immunohistochemistry) and of GAP43 mRNA (detected by in situ hybridization) were compared in the thalamus of adult rats between $1 \mathrm{~d}$ and $180 \mathrm{~d}$ after making a stab lesion or after implanting a peripheral nerve autograft. Stab injury is a sufficient stimulus to cause a transient upregulation in GAP-43 expression by neurons in the thaiamus (both around the graft tip and in particular in the thalamic reticular nucleus) in the first week after injury but this response is both prolonged, and enhanced in the presence of a peripheral nerve graft. In addition, we demonstrate directly, by double labelling, that neurons of the thalamic reticular nucleus displaying high levels of the mRNA for GAP-43, have axons regenerating in the distal portion of the graft. These findings lend direct support to the hypothesis that upregulation of the GAP-43 gene is essential for prolonged regenerative axonal growth. We also demonstrate GAP-43 protein in graft Schwann cells and in brain astrocytes close to the site of graft implantation.
\end{abstract}

[Key words: CNS regeneration, peripheral nerve grafts, CNS injury, thalamic reticular nucleus, GAP-43, GAP-43 mRNA]

Failure of axonal regeneration following injury in the adult mammalian CNS remains incompletely understood. Because many types of CNS neuron are able to regenerate injured axons into segments of grafted peripheral nerve (e.g., Aguayo, 1985) we know that this failure is not necessarily due to an intrinsic incapacity for regenerative growth, but may be due to the environment of the injured axon. It is, however, clear, that in the

Received May 16, 1994; revised Oct. 19, 1994; accepted Nov. 23, 1994.

We thank Dr. P. Emson (MRC Babraham, UK) for providing the alkalinephosphatase labeled GAP-43 probe and Drs. Stephen W. Davies (UCL, London, UK) and Stephen P.Hunt (MRC Cambridge, UK) for providing the GAP-43 probe for the radioactive in situ hybridization experiments. We also thank $M$. Turmaine and S. Miah for technical help and the Commission of European Communities (Science Plan), the MRC, the Nuffield Foundation, and the Wellcome Trust for financial support.

Correspondence should be addressed to Dr. Elisabetta Vaudano, Department of Anatomy and Developmental Biology, University College London, Gower Street, London WCIE 6BT, United Kingdom.

Copyright $(\mathcal{C} 1995$ Society for Neuroscience $0270-6474 / 95 / 153594-18 \$ 05.00 / 0$ presence of a peripheral nerve graft, some CNS neurons display a much greater regenerative propensity than others (Aguayo, 1985; Benfey et al., 1985; Morrow et al., 1993), raising the possibility that CNS neurons may differ in their intrinsic capacity to mount a regenerative response and/or may vary in their ability to respond to factors present in peripheral nerve grafts (Fawcett, 1992).

Here we focus on the growth associated protein GAP-43 which is strongly expressed throughout the CNS and PNS during development (Neve et al., 1987; Chong et al., 1992), but thereafter is expressed in significant amounts only in restricted parts of the ncrvous system (Kruger et al., 1993). The indirect evidence for a role of GAP-43 in axon growth is substantial (Zuber et al., 1989, Baetge and Hammang, 1991; Shea et al., 199i; Jap et al., 1992). Furthermore it is clear that during axon regeneration PNS neurons produce large amounts of GAP-43 (Skene and Willard, 1981a; Hoffman, 1989) whereas several early reports indicated that mammalian CNS neurons do not increase GAP-43 production after axotomy (Skene and Willard, 1981b; Skene, 1984), focusing attention on the possibility that inability to upregulate GAP-43 might provide an explanation for the limited regenerative capacity of CNS neurons following axotomy. More recently, however, it has been shown that GAP43 levels do increase in some axotomized CNS neurons, particularly if the lesion is close to the cell body (Doster et al., 1991; Tetzlaff et al., 1991) and in regenerating CNS axons around and within peripheral nerve grafts (Campbell et al., 1991). However, it is not known if thalamic neurons upregulate GAP-43 synthesis as a response to injury per se, or if the continuous presence of a graft is required to induce, enhance or sustain such a response. Moreover, it is not established if neurons with a high propensity to regenerate their axons along a peripheral nerve graft also have the ability to upregulate GAP43 after lesion and/or in the presence of a peripheral nerve graft. We have therefore compared the levels of GAP-43 protein and mRNA in the thalamus of adult rats after a stab wound and after the implantation of segments of autologous sciatic nerve. We find that stab injury is itself a sufficient stimulus for a transient increase in GAP-43 in the thalamus around the lesion but this response is both enhanced and prolonged in the presence of a peripheral nerve graft. We also show that the GAP-43 gene is selectively upregulated in TRN neurons in the presence of a peripheral nerve graft.

Some of the results have been briefly reported previously (Campbell et al., 1992b; Vaudano et al., 1992a,b, 1993a,b). 


\begin{tabular}{|c|c|c|c|c|c|c|c|c|c|}
\hline \multirow{2}{*}{$\begin{array}{l}\text { Animal } \\
\text { number } \\
\text { and } \\
\text { sur- } \\
\text { vival }\end{array}$} & \multirow{2}{*}{$\begin{array}{l}\text { Probe } \\
\text { used }\end{array}$} & \multirow[b]{2}{*}{ Lesion position } & \multicolumn{6}{|c|}{$\begin{array}{l}\text { Distribution of cells expressing } \\
\text { high levels of GAP- } 43 \text { mRNA }\end{array}$} & \multirow{2}{*}{$\begin{array}{l}\text { Total } \\
\text { number } \\
\text { of } \\
\text { labeled } \\
\text { cells }\end{array}$} \\
\hline & & & LP & MG & Po & TRN & VB & $\mathrm{ZI}$ & \\
\hline \multicolumn{10}{|l|}{ EV135 } \\
\hline $\begin{array}{c}1 \mathrm{~d} \\
\mathrm{EV} 136\end{array}$ & RL & $\mathrm{Co}, \mathrm{Hi}, \mathrm{LP}, \mathrm{Po}$ & - & - & - & - & - & - & \\
\hline $\begin{array}{c}2 \mathrm{~d} \\
\mathrm{EV} 90\end{array}$ & RL & Co, Hi, LP, Po, MG & - & - & - & - & - & - & \\
\hline $\begin{array}{c}5 \mathrm{~d} \\
\text { EV124 }\end{array}$ & $\mathrm{AP}$ & $\mathrm{Co}, \mathrm{Hi}, \mathrm{LP}, \mathrm{Po}, \mathrm{APT}, \mathrm{MG}, \mathrm{ZI}$ & 134 & 88 & 71 & 6 & - & 32 & 331 \\
\hline $\begin{array}{c}6 \mathrm{~d} \\
\text { EV94 }\end{array}$ & RL & CO, Hi, LP, TRN, VB & + & - & + & + & + & - & \\
\hline $\begin{array}{c}7 \mathrm{~d} \\
\mathrm{EV} 61\end{array}$ & $\mathrm{AP}$ & Co, Hi, LP, Po, APT, MG, ZI & 4 & - & 14 & - & - & 14 & 32 \\
\hline $\begin{array}{l}12 \mathrm{~d} \\
\text { EV95 }\end{array}$ & RL & Co, Hi, LP, LG, MG & - & - & - & - & - & - & \\
\hline $\begin{array}{l}13 \mathrm{~d} \\
\mathrm{EV} 100\end{array}$ & AP & Co, Hi, LP, VB, Po & - & - & - & - & - & - & \\
\hline $\begin{array}{l}17 \mathrm{~d} \\
\text { EV } 98\end{array}$ & $\mathrm{AP}$ & Co, Hi, LP, Po & - & - & - & - & - & - & \\
\hline $30 \mathrm{~d}$ & AP & Co, Ili, LP, Po, MG, ZI & - & - & - & - & - & - & \\
\hline
\end{tabular}

Distribution data derive from experiments with both radioactively labeled (RL) and alkaline phosphatase-labeled (AP) probes, but numerical data are based only on experiments with the AP probe. Abbreviations: APT, anterior pretectum; Co, cerebral cortex; Hi, hippocampus; LG, lateral geniculate nucleus; LP, lateral posterior nucleus; MG, medial geniculate complex; Po, posterior nucleus; SC, superior colliculus; SN, substantia nigra; TRN, thalamic reticular nucleus; VB, ventrobasal complex; ZI, zona incerta.

\section{Materials and Methods}

Animals. All the experimental procedures were carried out on adult female Sprague-Dawley rats (body weight $180-300 \mathrm{gm}$ ) deeply anesthetized with $2 \%$ halothane (Fluothane, ICI, UK).

Surgical procedures. For all procedures the animals were secured in a stereotaxic frame. For the stab wound lesions a craniotomy and incision in the dura were made, and a metal needle (gauge 26) was pushed vertically into the brain to a depth of $7 \mathrm{~mm}$ from the surface, $4-4.5 \mathrm{~mm}$ caudal and 2.5-3.0 mm lateral to bregma. The needle was inserted and retracted three to five times along a single dorsoventral track to create an extensive mechanical lesion in the left caudolateral thalamus.

For the grafting experiments, the tibial branch of the sciatic nerve was exposed in the right thigh and a segment of nerve $1.5-2 \mathrm{~cm}$ in length was excised. Using a fine glass micropipette the proximal end of the nerve segment was pushed vertically into the left thalamus, at the same coordinates and to the same depth as for the stab wounds. The graft was secured to the dura by a single 10/0 suture and its distal end was left free beneath the scalp.

Immunocytochemistry. After survival times between 4 and $180 \mathrm{~d}$ post operation (dpo) (see Tables 3 and 4) animals were overdosed with Sagatal (1.0-1.5 $\mathrm{ml} / \mathrm{kg}$, i.p.; Rhône Mérieux Ltd., UK) and then perfused with fixative solutions through the left cardiac ventricle.

For light microscopy the animals were perfused with $200-300 \mathrm{ml}$ of normal saline followed by $500 \mathrm{ml}$ of $4 \%$ paraformaldehyde in $0.1 \mathrm{M}$ phosphate buffer, at room temperature. The brains were removed and kept in $30 \%$ sucrose in $0.1 \mathrm{M}$ phosphate buffer at $4^{\circ} \mathrm{C}$ until they sank. Sections were cut on a sliding freezing microtome at a nominal thickness of $40 \mu \mathrm{m}$ and were collected in $0.1 \mathrm{M}$ phosphate buffer. After incubation for I hr in blocking solution ( $2 \%$ normal horse serum, $0.5 \%$ bovine serum albumin, $0.05 \%$ Triton $\mathrm{X}-100$ in phosphate-buffered saline) the sections were reacted for $48 \mathrm{hr}$ at $4^{\circ} \mathrm{C}$ with a monoclonal antibody, 9-1E12, which recognizes all forms of GAP-43 (Schreyer and Skene, 1991), diluted 1:25000-1:30000 in blocking solution. The reaction product was visualized using the avidinbiotin-peroxidase procedure (Elite ABC kit, Vector Laboratories, Oregon). Control sections were incubated with blocking solution, or with normal mouse serum (at dilutions of 1:25000-1:30000) in place of the primary antibody. The sections were finally mounted on subbed slides, air dried, cleared, and placed under a coverslip.
For electron microscopy four animals with stab wound lesions at $7-$ 12 dpo and six animals with autografts at $7-21$ dpo were perfused with $0.1 \mathrm{M}$ phosphate buffer rinse $(100 \mathrm{ml})$ followed by a mixture of $4 \%$ paraformaldehyde and $0.1 \%$ glutaraldehyde in $0.1 \mathrm{M}$ phosphate buffer $(500 \mathrm{ml})$, at room temperature. The brains were removed and cut coronally at $50-100 \mu \mathrm{m}$ on a Vibroslice. After incubation for $1 \mathrm{hr}$ in blocking serum (without Triton $\mathrm{X}-100$ ), the sections were reacted as above except that the primary antibody was used at a dilution of 1:3000060,000 . Following the immunoreaction, the sections were rinsed in 0.1 $\mathrm{M}$ sodium cacodylate buffer ( $\mathrm{pH} 7.4)$, osmicated $\left(1 \% \mathrm{OsO}_{4}\right.$ in $0.1 \mathrm{M}$ sodium cacodylate buffer for $45 \mathrm{~min}$ ), contrasted in buffered uranyl acetate ( $2 \%$ for 30 mins), dehydrated and embedded in Araldite. Ultrathin sections were cut on a Reichert Ultracut ultramicrotome and were viewed, without further staining, in a Jeol 1010 electron microscope.

In situ hybridization histochemistry. After survival times of between 1 and 30 dpo (see Tables 1 and 2) animals were terminally reanesthetized cither by ovcrdose with ether or with $2 \%$ halothane, and decapitated; the brain was removed and rapidly frozen on dry ice; sections were cut at $12-20 \mu \mathrm{m}$ in a cryostat and postfixed in cold $\left(4^{\circ} \mathrm{C}\right) 4 \%$ paraformaldehyde in phosphate buffered saline, dehydrated through a graded series of alcohols and delipidated in chloroform.

For radioactive in situ hybridization we used a 48 mer oligodeoxynucleotide with a nucleotide sequence complementary to that of nucleotides 106-153 of rat GAP-43 CDNA (Basi et al., 1987) kindly provided by Dr S. P. Hunt (MRC Laboratory of Molecular Biology, Cambridge, UK). The probe was 3 -end-labeled with ${ }^{35} \mathrm{~S}$-dATP $(1200 \mathrm{Ci} / \mathrm{mmol}$, New England Nuclear-Du Pont) using terminal deoxynuclcotide transferase (Pharmacia). Hybridization was carried out overnight in 50\% formamide in $4 \times$ standard saline citrate (SSC), 10\% dextran sulfate, and 5 $\mathrm{mg} / \mathrm{ml}$ polyadenylic acid, $120 \mathrm{mg} / \mathrm{ml}$ heparin, $4 \mathrm{mg} / \mathrm{ml}$ acid/alkali cleaved salmon sperm DNA, $0.5 \mathrm{M}$ sodium phosphate, and $0.1 \mathrm{~m}$ sodium pyrophosphate at $42^{\circ} \mathrm{C}$ with probe added at $1 \mathrm{pg} / \mathrm{ml}$. Sections were washed at $55^{\circ} \mathrm{C}$ in $1 \times \mathrm{SSC}$ and were exposed to Kodak XAR-5 film at room temperature for $2 \mathrm{~d}$ before being dipped in Ilford K-5 emulsion (diluted $1: 1$ in $0.5 \%$ glycerol) and exposed at $4^{\circ} \mathrm{C}$ for $10 \mathrm{~d}$. Sections were developed with Kodak D19, fixed with $30 \%$ sodium thiophosphate, counterstained with $1 \%$ thionin, cleared, and mounted under a 
Figure 1. Diagrams showing the distribution of neurons expressing high levels of GAP-43 mRNA (small black dots) $5 \mathrm{~d}$ after a stab lesion (A, stippled area) and $5 \mathrm{~d}$ after the implantation of a peripheral nerve graft $(B$, solid black area) in the caudal thalamus of adult rats. Hybridization in both cases was with an alkaline phosphatase labeled probe. The three drawings for each experimental paradigm represent a rostral (top)-caudal (bottom) series of coronal sections through the diencephalon. Numbers illustrate the approximate level of each section according to the stereotaxic atlas of Paxinos and Watson (1986). Note that both lesion and graft induce GAP-43 upregulation but that the graft induces a much larger number of neurons to display activity of the GAP-43 gene than the lesion. $A$, animal EV90; $B$, animal GC183. Sections 3.4 $(A)$ and $5.2(B)$ correspond approximately to the sections from which the micrographs in Figure $2, A$ and $B$, respectively, were taken.
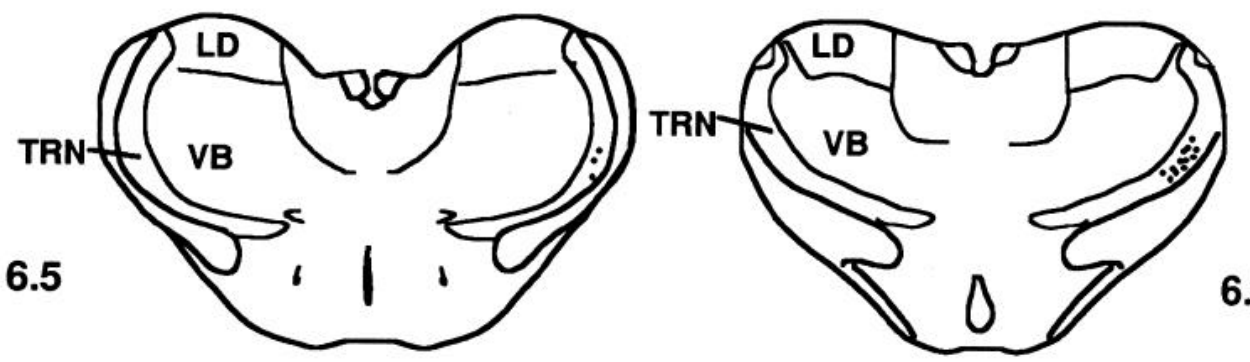

6.3
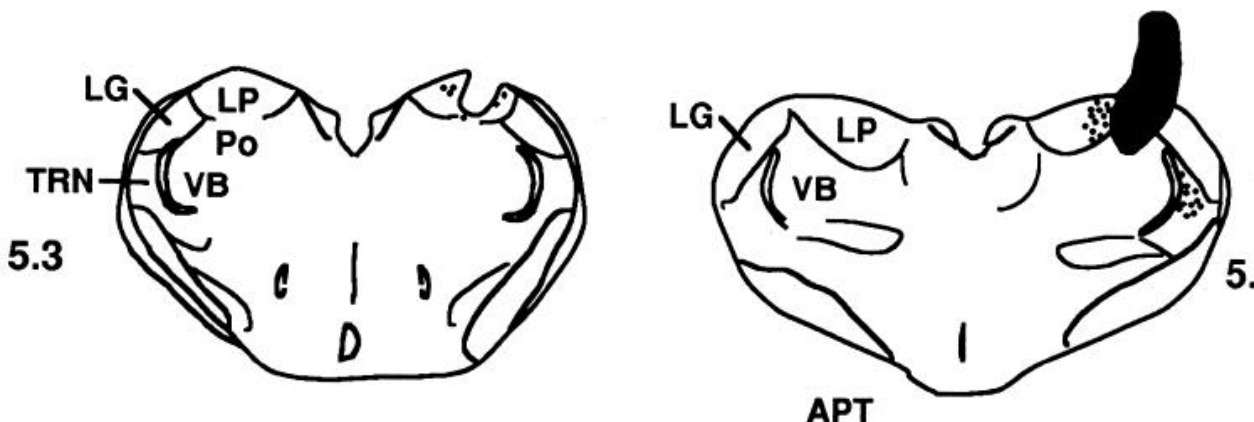

5.2
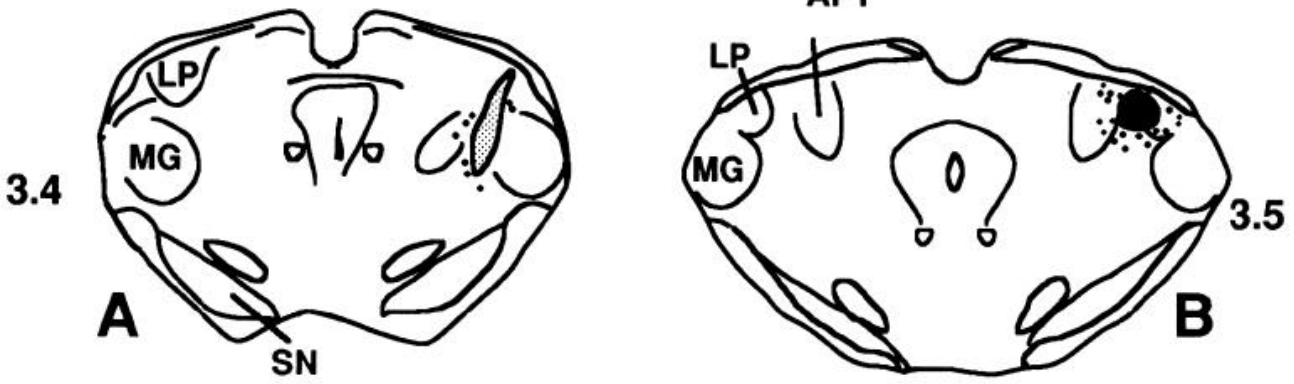

lesion
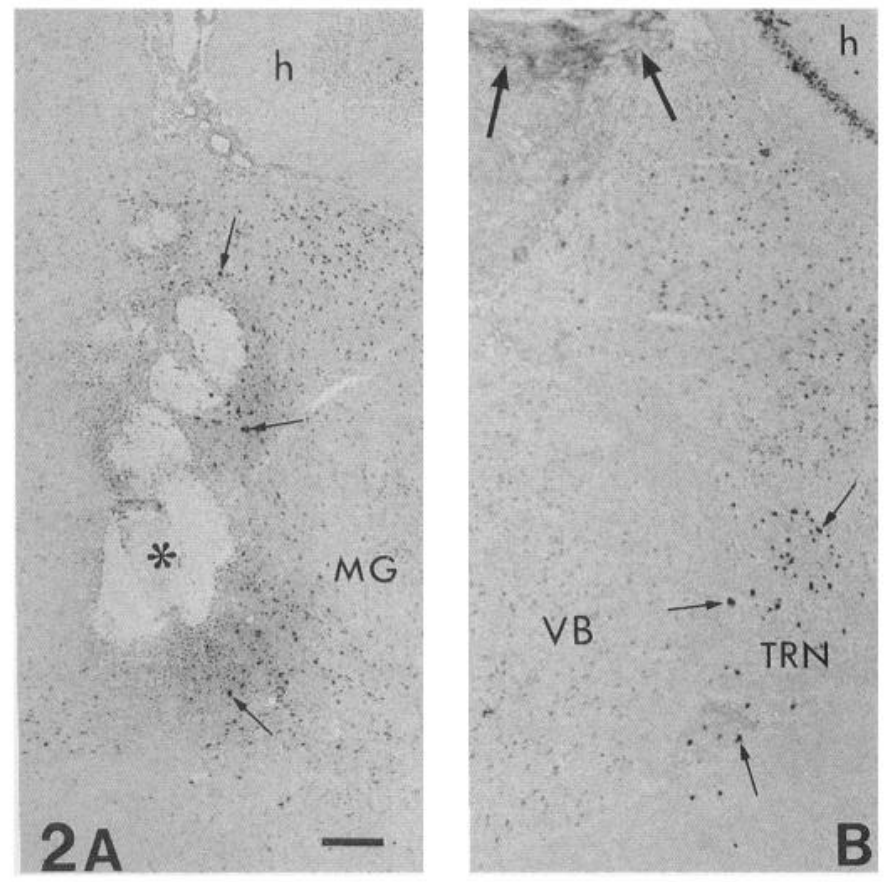

coverslip. Material was examined under both bright- and dark-field illumination. Hybridization of control sections with 20 -fold excess of cold probe together with labelled probe produced no detectable signal (e.g., Figs. $3 C, 4 C$ ).

For nonradioactive in situ hybridization we used an alkaline phosphatase linked 39-mer oligodeoxynucleotide corresponding to nucleotides 119-157 of rat GAP-43 cDNA (Basi et al., 1987), kindly provided by Dr. P. C. Emson (AFRC, Babraham, UK). Sections were hybridized overnight at $37^{\circ} \mathrm{C}$ in $50 \%$ formamide in $4 \times \mathrm{SSC}, 10 \%$ dextran sulfate, $4 \mathrm{mg} / \mathrm{ml}$ acid/alkali cleaved salmon sperm DNA using a final concentration of probe of $4 \mathrm{fmol} / \mathrm{ml}$. Sections were rinsed in $1 \times \mathrm{SSC}$ at $55^{\circ} \mathrm{C}$, and bound probe was visualized by the color reaction of alkaline phosphatase on the substrates nitroblue tetrazolium and BCIP (5-bromo-4chloro-3-indolyl-phosphate). Sections were then mounted under a coverslip. Control sections hybridized without the probe did not produce any detectable staining.

$\leftarrow$

Figure 2. Light micrographs showing a few neurons (small arrows) expressing high levels of GAP-43 mRNA in the medial geniculate nucleus $(M G)$ adjacent to a stab lesion (the asterisk indicates an area of vacuolization and disruption which marks the site of the lesion; $A$ ) and in the thalamic reticular nucleus (TRN) close to a graft (the tip of which is indicated by the large arrows; $B$ ). In both cases the animal was killed $5 \mathrm{~d}$ after making the lesion or inserting the graft, and alkaline phosphatase probes were used. $h$, hippocampus; $V B$, ventrobasal nucleus. $A$, animal EV90; $B$, animal GC183. Scale bar: $A, 200 \mu \mathrm{m} ; B, 100 \mu \mathrm{m}$. 

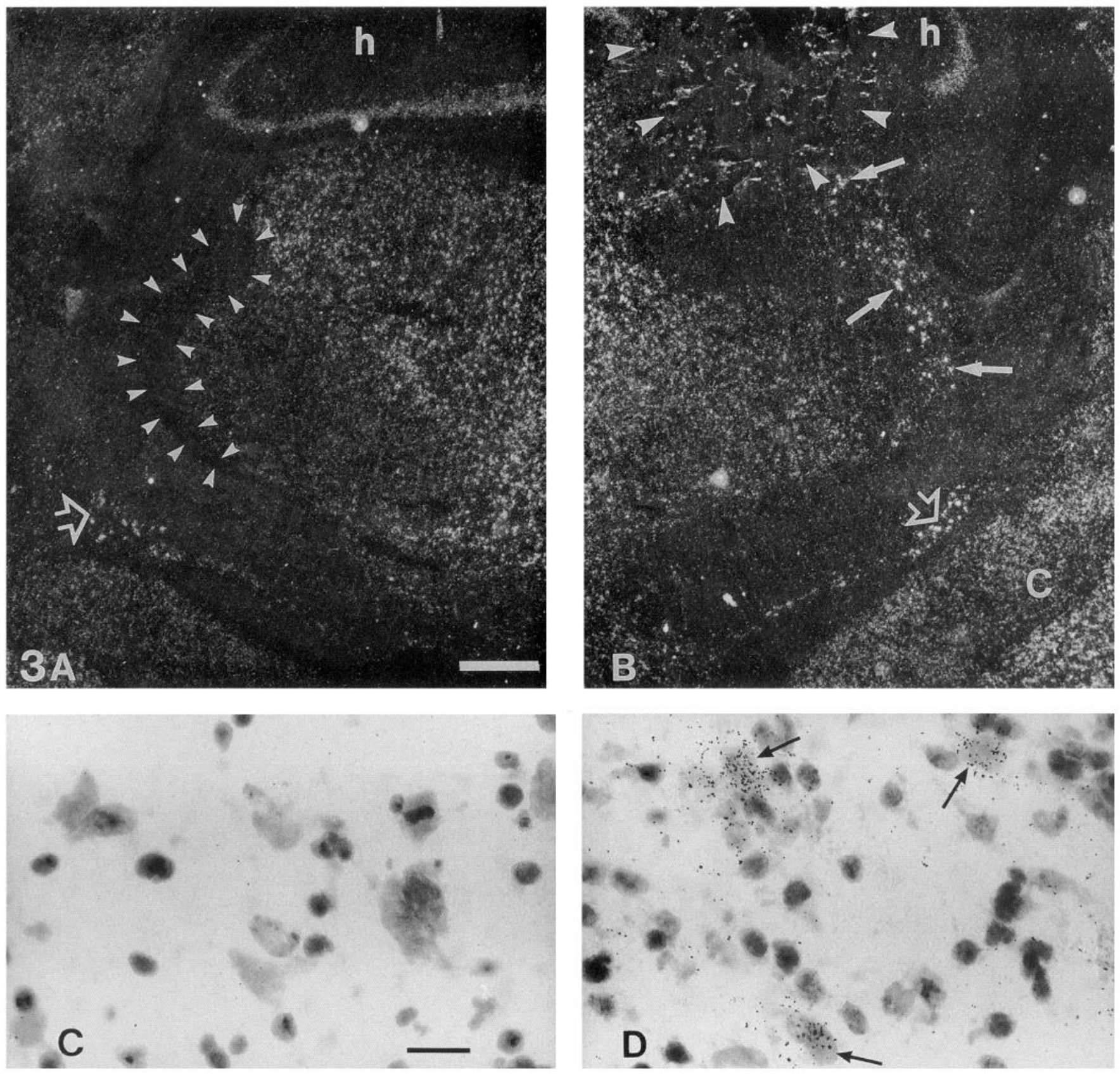

Figure 3. Dark-field $(A, B)$ and bright-field $(C, D)$ micrographs of the thalamus $6 \mathrm{~d}$ after a stab lesion and in situ hybridization with a radioactive probe for GAP-43 mRNA. $A$ and $B$ show corresponding parts of the thalamus contralateral $(A)$ and ipsilateral $(B)$ to the lesion (outlined by large arrowheads in B). Many TRN neurons on the side of the lesion are heavily labeled (e.g., at arrows) demonstrating the upregulation by these neurons of GAP-43 mRNA. Some of the labeled neurons are shown at higher magnification in $D$ (arrows); note that smaller, presumably glial cells are unlabeled. It is noteworthy that many neurons of the dorsal thalamus, basal nucleus of Meynert (open arrow), hippocampus $(h)$, and the cerebral cortex $(C)$ on both sides of the brain express GAP-43 mRNA. However, the TRN contralateral to the lesion (outlined by arrowheads in A) is entirely devoid of label. $C$ (magnification as in $D$ ) shows part of the TRN on the same side as the lesion, in a section processed with cold probe. Sections counterstained with thionin. Animal EV124. Scale bars: $A$ and $B, 500 \mu \mathrm{m} ; C$ and $D, 10 \mu \mathrm{m}$.

Double-labeling experiments. Three rats were implanted with tibial nerve autografts (as described above). After 1.5-2 months they were anesthetized with halothane and a mixture of $0.2 \mu \mathrm{l}$ cholera toxin subunit B conjugated to horseradish peroxidase (CT-HRP, List Biological Labs, California) and $0.1 \mu \mathrm{l}$ of wheat germ agglutinin conjugated to HRP (WGA-HRP, Sigma) in about $0.3 \mu$ l of sterile water was slowly injected with a micropipette-tipped $5 \mu \mathrm{l}$ Hamilton syringe into the exposed graft about $2-3 \mathrm{~mm}$ from the craniotomy. The rats were killed with ether 2-3 d later and the brains rapidly removed and frozen in dry ice. Alternate cryostat sections, cut at $12 \mu \mathrm{m}$, were mounted on two sets of slides and fixed for $5 \mathrm{~min}$ in $4 \%$ paraformaldehyde. One set of sections was processed for the tetramethylbenzidine technique of Mesulam (1978) to reveal the HRP reaction product, and counterstained with thionine before mounting with a coverslip, the other set of sections was dehydrated and processed for radioactive in situ hybridization using the same GAP-43 probe and method as described above. 

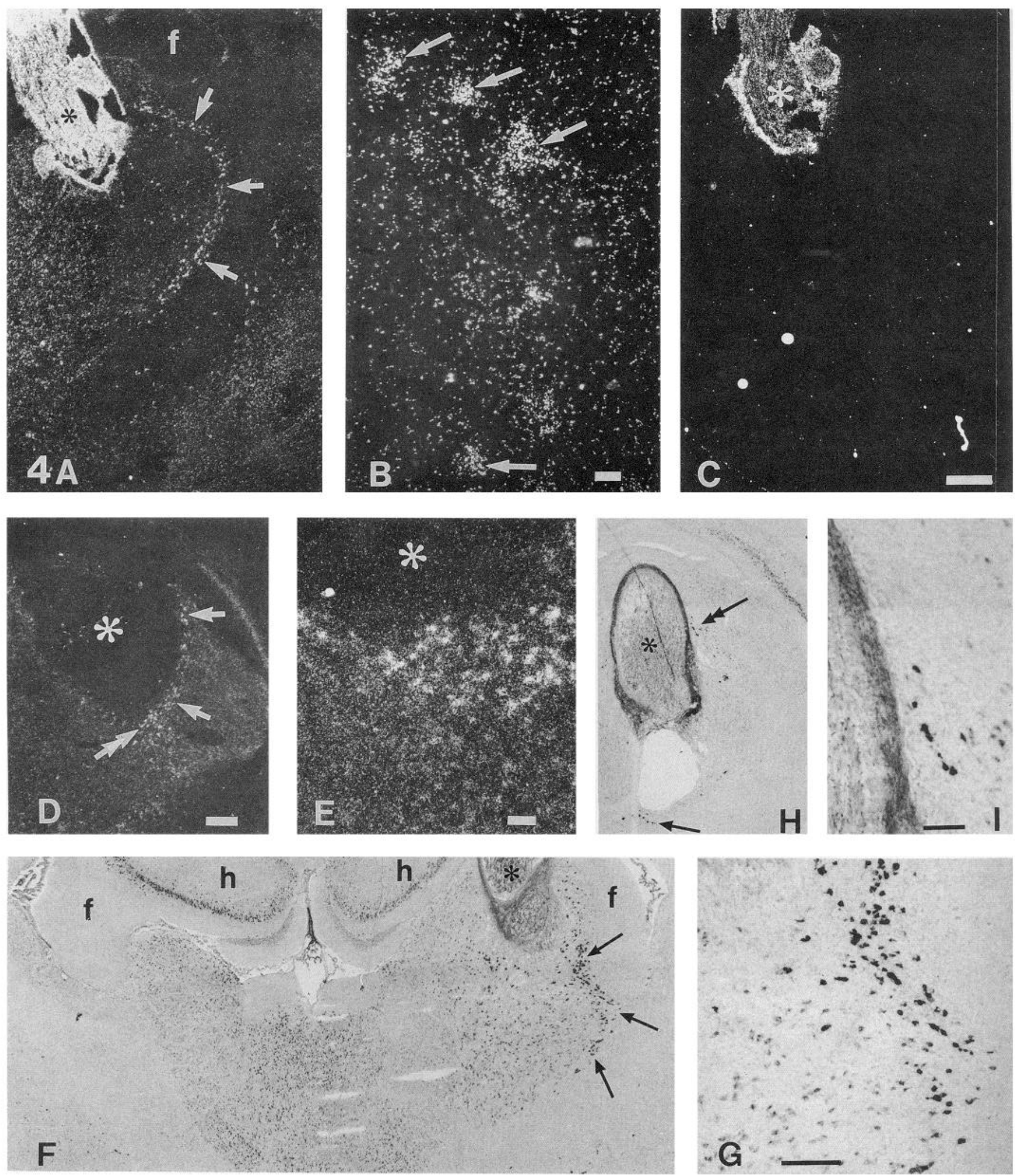

Figure 4. Neurons expressing high levels of GAP-43 mRNA in the TRN $(A, B, F, G)$ posterior thalamic nucleus (Po) and the medial geniculate (MG) nucleus $(D, E, H, I)$ of adult rats $6 \mathrm{~d}(A-C), 12 \mathrm{~d}(D, E), 17 \mathrm{~d}(F, G)$, and $30 \mathrm{~d}(H, I)$ after implantation of peripheral nerve graft (*). A-C, Dark-field micrographs of TRN neurons (arrows) labeled with a radiolabeled probe at low $(A)$ and high $(B)$ magnifications and in a close serial section from the same brain, unlabeled after treatment with cold probe $(C) . D$ illustrates GAP-43 mRNA + neurons (arrows) in the MG and around the tip of the graft $(*)$. The area indicated by a double arrow is shown at higher magnification in a close serial section in $E$. $F$ shows a low magnification view of neurons labeled with an alkaline phosphatase-conjugated probe in the brain close to the graft. Note that the labeling is strongest in the TRN (e.g., arrows) and in small numbers of other neurons close to the graft, and that the TRN on the contralateral side is devoid of labeled cells in the corresponding positions. Labeled TRN neurons from $F$ are shown at higher magnification in $G$. $H$ illustrates a few labeled 


\begin{tabular}{|c|c|c|c|c|c|c|c|c|c|}
\hline \multirow{2}{*}{$\begin{array}{l}\text { Animal } \\
\text { number } \\
\text { and } \\
\text { sur- } \\
\text { vival }\end{array}$} & \multirow{2}{*}{$\begin{array}{l}\text { Probe } \\
\text { used }\end{array}$} & \multirow[b]{2}{*}{ Position of graft } & \multicolumn{6}{|c|}{$\begin{array}{l}\text { Position of cells with high levels } \\
\text { of GAP- } 43 \text { mRNA }\end{array}$} & \multirow{2}{*}{$\begin{array}{l}\text { Total } \\
\text { number } \\
\text { of } \\
\text { labeled } \\
\text { cells }\end{array}$} \\
\hline & & & LP & MG & Po & TRN & VB & $\mathrm{ZI}$ & \\
\hline \multicolumn{10}{|l|}{ GC183 } \\
\hline $\begin{array}{l}5 d \\
\text { EV } 105\end{array}$ & $\mathrm{AP}$ & Co, Hi, LP, Po, VB, MG & 319 & - & 47 & 172 & 17 & - & 555 \\
\hline $\begin{array}{c}6 \mathrm{~d} \\
\mathrm{EV} 60\end{array}$ & RL & Co, Hi, LP, TRN, VB, ZI & + & - & + & + & + & - & \\
\hline $\begin{array}{l}12 \mathrm{~d} \\
\text { EV93 }\end{array}$ & RL & Co, Hi, LP, Po, MG, ZI & + & + & + & - & - & + & \\
\hline $\begin{array}{l}13 \mathrm{~d} \\
\mathrm{EV} 101\end{array}$ & AP & $\mathrm{Co}, \mathrm{Hi}, \mathrm{LP}, \mathrm{VB}, \mathrm{Po}$ & 22 & 49 & 162 & 83 & 83 & 59 & 460 \\
\hline $\begin{array}{l}17 \mathrm{~d} \\
\text { EV86 }\end{array}$ & $\mathrm{AP}$ & $\mathrm{Co}, \mathrm{Hi}, \mathrm{LP}, \mathrm{TRN}$ & 129 & - & - & 473 & 99 & - & 701 \\
\hline $\begin{array}{l}22 \mathrm{~d} \\
\text { EV85 }\end{array}$ & $\mathrm{AP}$ & $\mathrm{Co}, \mathrm{Hi}, \mathrm{LP}, \mathrm{Po}, \mathrm{MG}$ & 42 & 37 & 31 & 71 & - & - & 181 \\
\hline $\begin{array}{l}22 \text { d } \\
\text { EV } 99\end{array}$ & $\Lambda \mathrm{P}$ & $\mathrm{Co}, \mathrm{Hi}, \mathrm{LP}, \mathrm{VB}$ & 8 & - & 5 & 18 & 18 & 1 & 50 \\
\hline $30 \mathrm{~d}$ & $\mathrm{AP}$ & $\mathrm{CO}, \mathrm{Hi}, \mathrm{LP}, \mathrm{VB}, \mathrm{Po}$ & 14 & 29 & 76 & 6 & 4 & 76 & 205 \\
\hline
\end{tabular}

Distribution data derive from experiments with both radioactively labeled (RL) and alkaline phosphatase-labeled (AP) probes, but numerical data are based only on experiments with the AP probe. For abbreviations see Table 1 .

\section{Results}

\section{In situ hybridization}

GAP-43 mRNA expression in the intact thalamus

We examined the distribution of GAP-43 mRNA in the thalamus of two normal unoperated adult rats, in one case using the alkaline phosphatase (AP) conjugated probe, and in the other the radiolabeled probe ( $R L)$. The findings were similar in both animals and were similar to those reported recently by Kruger et al. (1993) and Yao et al. (1993). GAP-43 mRNA was expressed at low to moderate levels in all dorsal thalamic nuclei. However, the TRN showed only background labeling. Dorsal thalamic nuclei contralateral to a stab wound or a graft showed labeling patterns closely comparable to those found in the control animals (see Fig. $3 A$ ). With both probes, signal appeared to be associated exclusively with neurons.

\section{Expression of GAP-43 mRNA in the thalamus adjacent to a} stab wound

We examined five animals at survival times between 5 and 30 dpo using the AP labeled probe, and four animals at 1,2,6, and 12 dpo with the RL probe (Table 1). We obtained comparable results with the two methods.

At 1 and 2 dpo we did not observe upregulation of GAP-43 in the thalamus adjacent to the lesion. However, at 5 dpo (Figs. $1 A, 2 A$ ) and 6 dpo (Fig. 3B) sparse neuronal cell bodies showing increased expression of GAP-43 were found in an area up to a few hundred micrometers from the center of the lesion, in the lateral postcrior nucleus (LP), postcrior thalamic nuclcus (Po), anterior pretectum (APT), and the medial division of the medial geniculate nucleus (MG). Labeled neuronal perikarya were also apparent in the thalamic reticular nucleus (TRN), ipsilateral to the lesion and immediately adjacent and anterior to it (Figs. 1A, $3 B$ ). The TRN contralateral to the lesion showed no labeling in any animal (Fig. 3A). A few neurons expressing high levels of GAP-43 mRNA were also seen in the area immediately adjacent to the lesion in the 7 dpo animal (Table 1), although in this case labeled neurons were not seen in TRN. In all animals examined at survival times longer than $7 \mathrm{dpo}$, the expression of GAP-43 mRNA in the thalamus adjacent to the stab wound had returned to control levels. We never observed detectable levels of GAP43 mRNA in cells with the morphology or distribution pattern of central glia (Fig. 3D).

\section{Expression of GAP-43 $\mathrm{mRNA}$ in the thalamus adjacent to a graft}

We examined six animals at survival times between 5 and $30 \mathrm{dpo}$ using the AP conjugated probe and two animals, one at 6 and the other at 12 dpo with the RL probe (Table 2). As in the previous series of animals the two methods produced similar results. In contrast to what was found after simple mechanical lesion, at all survival times, even the longest, we found neurons expressing high levels of GAP-43 mRNA in the thalamus ipsilateral to the graft (Figs. $1 ; 2 B, 4 A, D, F, H ; 5 ; 6$ ). Such neurons were not present in corresponding areas of the contralateral thalamus (Figs. I, $4 F$, 5). The labeled cells were located either in the dorsal thalamic nuclei immediately adjacent to the graft tip or in the ipsilateral 


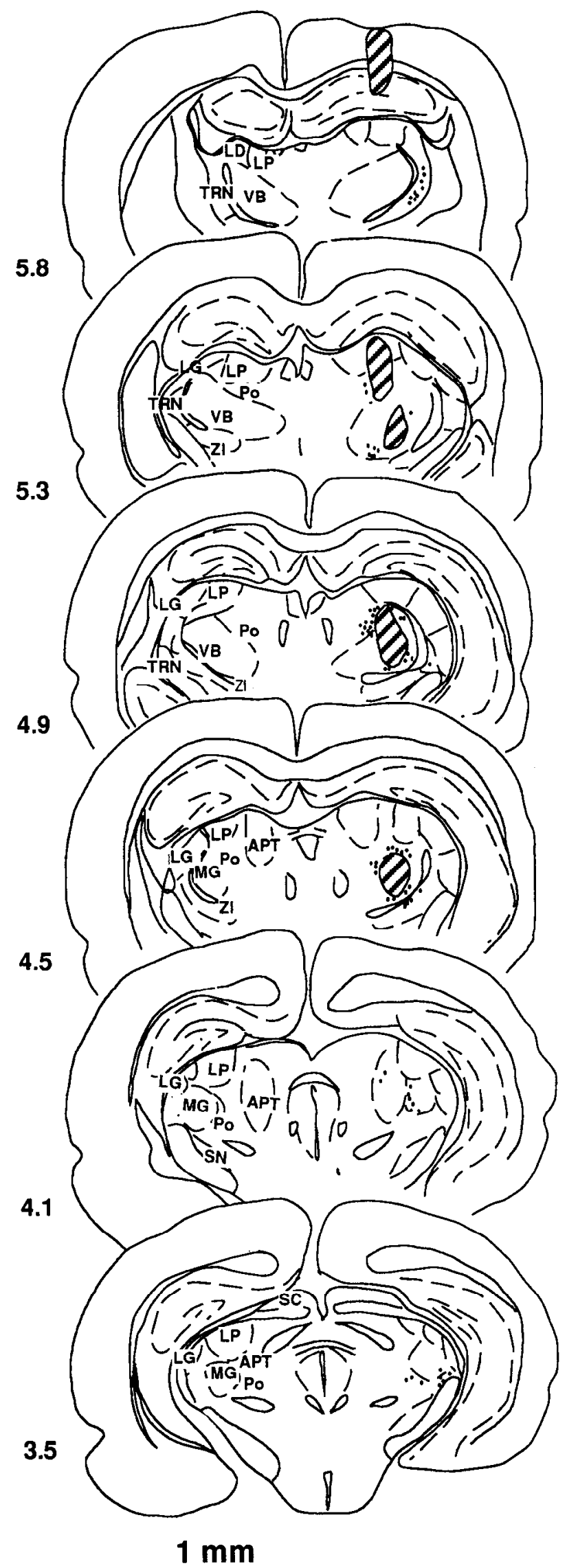

Figure 5. Diagram showing the distribution of neurons expressing high levels of GAP-43 mRNA as revealed by an alkaline phosphatase-

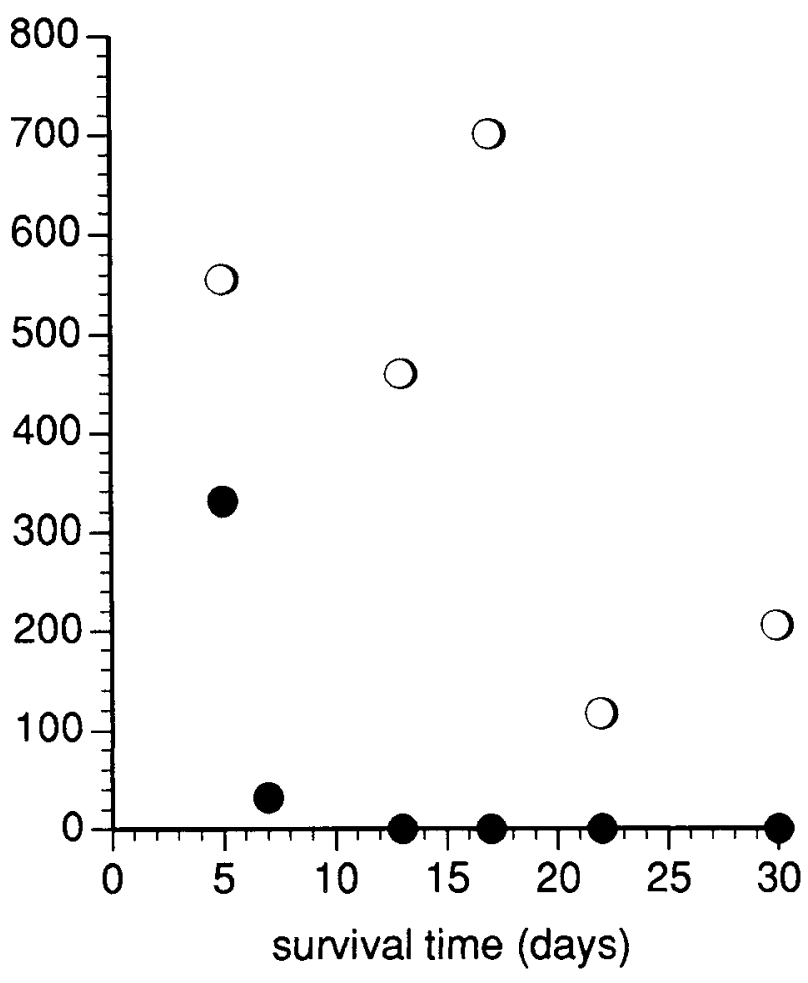

neurons expressing high levels of GAP-43 mRNA after lesion

\section{neurons expressing high levels of GAP-43 mRNA after PN graft}

Figure 6. The number of neurons expressing high levels of GAP-43 mRNA in the adult rat diencephalon after implantation of a graft (O) or after a stab lesion (O) at different postoperative survival times. Note that the increase in numbers of neurons expressing GAP-43 mRNA after a stab wound is smaller and more transient than the increase after implantation of a peripheral nerve segment, following which significant numbers of neurons are still expressing GAP-43 mRNA more than 4 weeks after graft insertion. The distribution of the neurons upon which the figure is based is shown in Tables 1 and 2. Note that counts of labeled neurons were made only in in situ hybridization material processed with the alkaline phosphatase probe.

labeled probe (small dots) in the diencephalon of an adult rat (EV99) $30 \mathrm{~d}$ after implantation of a peripheral nerve graft (hatched areas). Representative sections are shown in a rostral (top) to caudal (bottom) sequence and in each section all labeled neurons have been drawn. Numbers to the left of each figure correspond to the approximate levels of the sections as given in the atlas of Paxinos and Watson (1986). It is noteworthy that neurons labeled above background levels are not present in the cerebral cortex or hippocampus close to the graft as it traverses these structures. $A P T$, anterior pretectal nucleus; $L D$, lateral dorsal nucleus; $L G$, LGN; $L P$, lateral posterior nucleus; $M G$, medial geniculate nucleus; $P o$, posterior nucleus; $S C$, superior colliculus; $S N$, substantia nigra; $T R N$, thalamic reticular nucleus; $V B$, ventrobasal nucleus; $Z I$, zona incerta. 

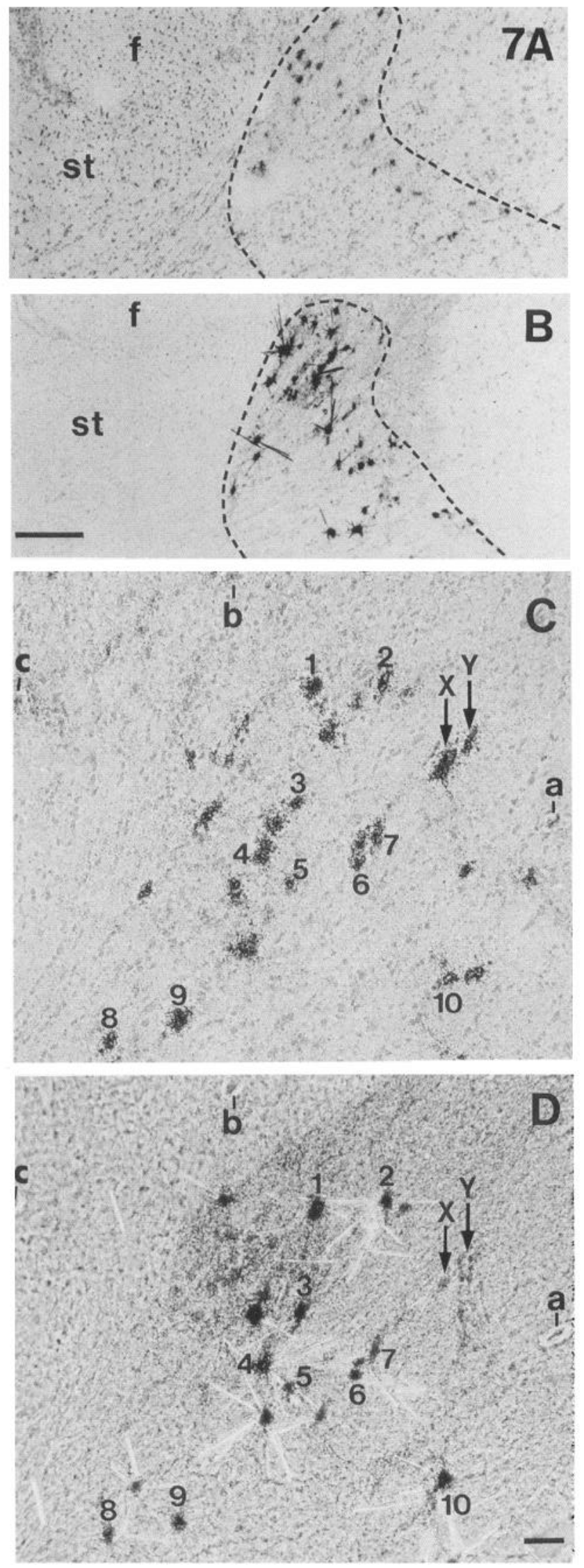

Figure 7. Light micrographs of the TRN of a rat, 6 weeks after the insertion of a tibial nerve graft into the ipsilateral thalamus and $2 \mathrm{~d}$
Table 3. Distribution of GAP-43-immunopositive cells after stab wound lesion in the left thalamus

\begin{tabular}{llll}
$\begin{array}{l}\text { Animal } \\
\text { number }\end{array}$ & Lesion position & $\begin{array}{l}\text { Sur- } \\
\text { vival }\end{array}$ & Cell labeling \\
\hline EV9 & Co, Hi, LP, Po, APT & 4 d & Yes (Po, APT) \\
EV24 & Co, Hi, LP, MG, APT, ZI & 7 d & Yes (Po, MG) \\
EV38 & Co, Hi, LP, Po, APT, SC & 7 d & Yes (Po, APT) \\
EV64 & Co, Hi, LP, Po, ZI & 7 d & Yes (MG) \\
TO1 & Co, Hi, LP, LG, Po, ZI & 7 d & Yes (Po, ZI) \\
TO2 & Co, Hi, LP, Po, TRN, VB & 7 d & Yes (Po, VB) \\
EV50 & Co, Hi, LP, Po, VB, TRN & 7 d & Yes (Po, VB) \\
EV33 & Co, Hi, LP, LG, Po, ZI & 9 d & No \\
EV61 & Co, Hi, LP, LG, MG, ZI & 12 d & Yes (MG) \\
EV39 & Co, Hi, LP, Po, VB, ZI & 14 d & No \\
EV83 & Co, Hi, LP, LG & 15 d & No \\
EV18 & Co, Hi, LG & 18 d & No \\
EV54 & Co, Hi, LP, Po, MG & 20 d & No \\
EV51 & Co, Hi, LP, Po, VB & $28 \mathrm{~d}$ & No \\
EV84 & Co, Hi, LP, LG & 32 d & No
\end{tabular}

For abbreviations see Table 1.

TRN (Figs. $1 B ; 2 B ; 4 A, B, D-I ; 5$ ). The position of the labeled cells in TRN varied according to the position of the graft tip in the thalamus, such that in the case of grafts ending in LP the labeled neurons were in dorsal TRN, while in case of grafts ending in the ventrobasal nucleus (VB) or in the most caudal thalamus, the GAP- 43 mRNA positive cells were in the ventral and caudal TRN. Cells expressing high levels of GAP-43 mRNA in the dorsal thalamus were only present within a limited distance from the graft tip (maximum 300-400 $\mu \mathrm{m}$ ), and the only nuclei in which we found labeled neurons up to a distance of $1.3 \mathrm{~mm}$ from the graft tip, were the TRN and, to a minor extent, the caudal part of the Po and adjacent medial division of the MG. The number of neurons expressing high levels of GAP-43 mRNA varied in the individual animals; however, at corresponding survival times we always found a larger number of GAP-43 mRNA positive neurons after peripheral nerve grafting than after simple me-

$\leftarrow$

after the application of CT-HRP/WGA-HRP to the distal portion of the graft. Alternate sections were reacted either for retrogradely transported HRP $(B, D)$ or by in situ hybridization for the presence of GAP-43 mRNA $(A, C) . A$ and $B$ are immediately adjacent sections at low magnification (TRN outlined by dashed lines); they show that the area of TRN containing retrogradely labeled cell bodies $(B)$ is coextensive with the area of TRN containing neurons heavily labeled for GAP-43 mRNA $(A) . C$ and $D$ show colocalization at the level of individual cells in higher magnification photomicrographs of a different pair of immediately serial sections. $C$ is a phase contrast image showing cells expressing high levels of GAP-43 mRNA; $D$ is a phase contrast image showing HRP reaction product. Blood vessels $a-c$ are indicated, and corresponding neurons are numbered $(I-I 0)$. Arrows $X$ and $Y$ indicate two double labeled neurons (only lightly labeled with HRP reaction product) giving rise to proximal dendrites in $C($ arrow $X)$ and $D($ arrow $Y)$. The long needle-like structures emanating from the HRP-labeled neurons in $B$ and $D$ are TMB artifacts resulting from deliberate over reaction of sections during histochemical processing ( $f$, fimbria; st, stria terminalis). Scale bars: $A$ and $B$ (same magnification), $100 \mu \mathrm{m} ; C$ and $D$ (same magnification), $50 \mu \mathrm{m}$. 

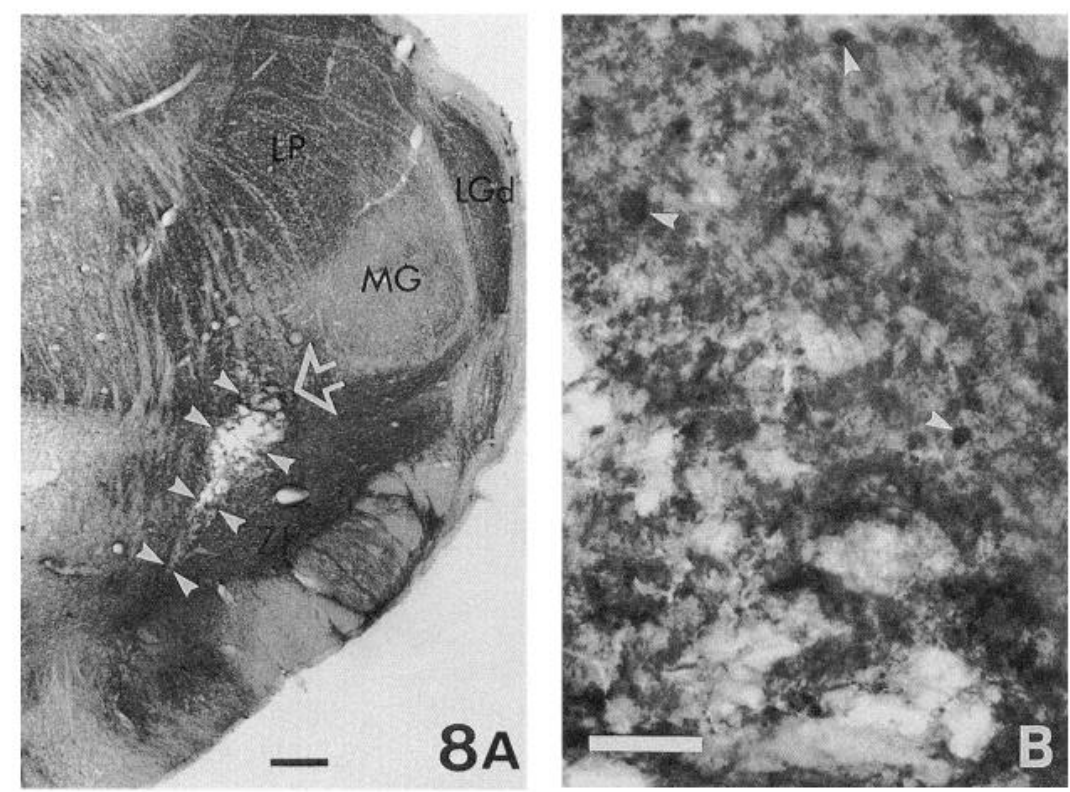

Figure 8. GAP-43 immunoreactive neuronal somata and axons in the diencephalon close to a stab lesion (arrowheads in $A$, stipple in $C$ and $F$ ) at postoperative day $7(A-E)$ and $12(F$, $G)$. A shows the ventralmost extremity of a stab lesion in the posterior nucleus and zona incerta. Note the moderate levels of GAP-43 protein in the dorsal LGN $(L G d)$ and in the zona incerta $(Z I)$ and in the lateral posterior nucleus (LP) and the slightly higher levels of the protein around the lesion. The area indicated by the open arrow is shown at higher magnification in $B$ where a few immunopositive presumptive neuronal cell bodies (arrowheads) are seen in an area of heavy neuropil labeling. $C-E$ show GAP-43 labeled neuronal cell bodies (arrows in $D$ ) and a beaded axon (arrows, E) adjacent to a lesion in the posterior nucleus $(\mathrm{Po})$ and zona incerta $(Z I)$ (stippled area in camera lucida drawing in $C$ ). Boxed areas in $C$ are shown in micrographs $D$ and $E$; in the case of $E$ the photomicrograph is rotated $90^{\circ}$ with respect to the box in $C$, and ventral is to the left in $E . F$ is a camera lucida drawing of a lesion (stippled area) between the LGN ( $L G)$ and medial geniculate nucleus $(M G)$ and intruding on both. The boxed region is illustrated by the photomicrograph in $G$ which shows a GAP-43 labeled neuron (arrow) giving rise to three processes within the lesioned area. $L G v$, ventral LGN. $A$ and $B$, animal EV24; $C-E$, animal EV50; $F$ and $G$, EV61. Scale bars: $A, 250 \mu \mathrm{m} ; B, 50$ $\mu \mathrm{m} ; D, 10 \mu \mathrm{m}$ for $D$ and $G ; E, 10 \mu \mathrm{m}$.
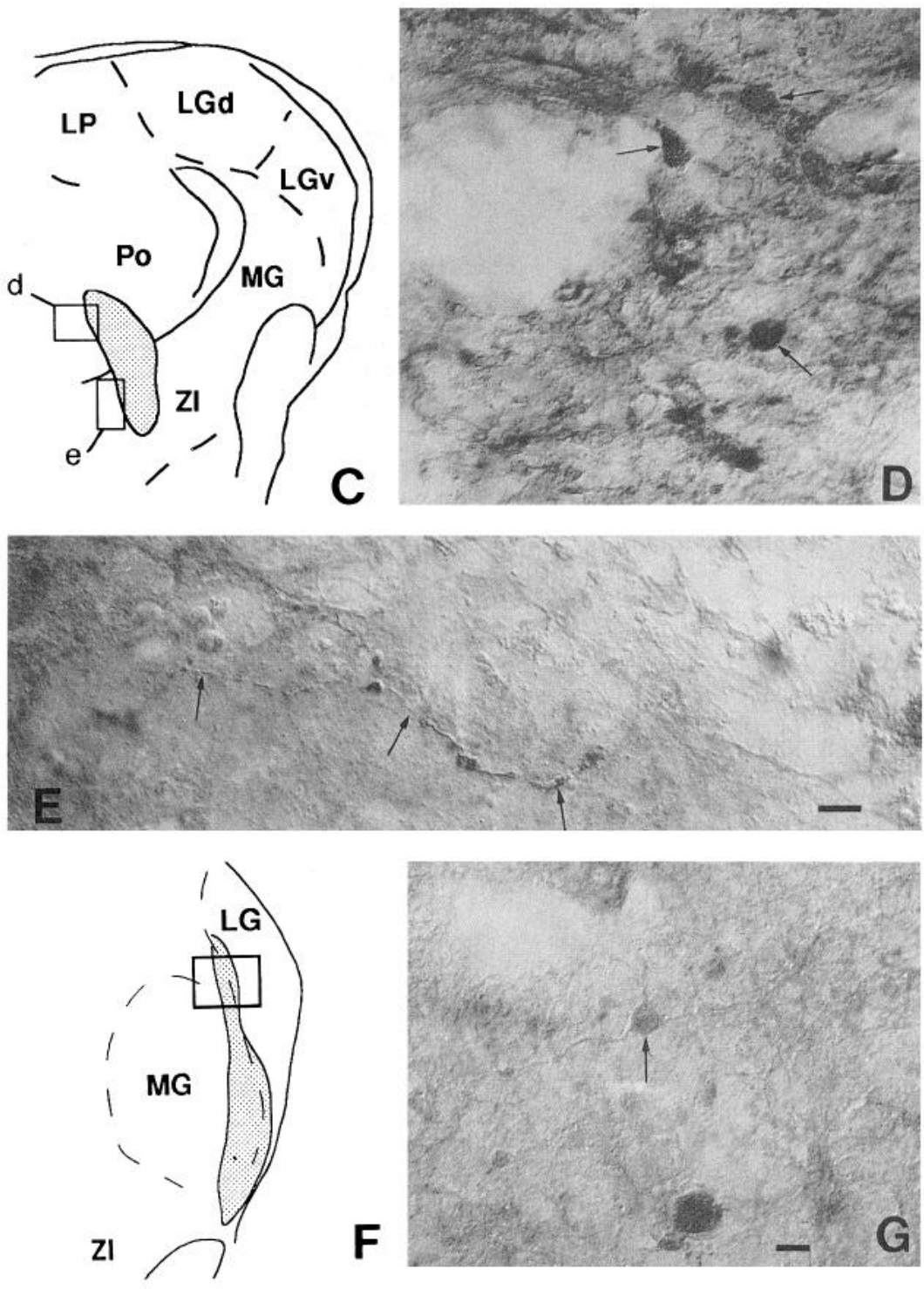


\begin{tabular}{|c|c|c|c|}
\hline $\begin{array}{l}\text { Animal } \\
\text { number }\end{array}$ & Graft position & Survival & Cell labeling \\
\hline EV46 & $\mathrm{Co}, \mathrm{Hi}, \mathrm{LP}, \mathrm{Po}$ & $7 d$ & No \\
\hline EV4 & $\mathrm{Co}, \mathrm{Hi}, \mathrm{LP}, \mathrm{Po}, \mathrm{APT}$ & $7 \mathrm{~d}$ & No \\
\hline EV70 & $\mathrm{Co}, \mathrm{Hi}, \mathrm{VB}, \mathrm{Po}, \mathrm{ZI}$ & $7 \mathrm{~d}$ & No \\
\hline EV76 & $\mathrm{Co}, \mathrm{Hi}, \mathrm{LP}$ & $7 \mathrm{~d}$ & No \\
\hline $\mathrm{GC} 173$ & $\mathrm{Co}, \mathrm{Hi}, \mathrm{Po}, \mathrm{MG}, \mathrm{APT}$ & $7 \mathrm{~d}$ & No \\
\hline TO6 & $\mathrm{Co}, \mathrm{Hi}, \mathrm{LP}, \mathrm{Po}, \mathrm{MG}$ & $7 \mathrm{~d}$ & No \\
\hline GC156 & $\mathrm{Co}, \mathrm{Hi}, \mathrm{LP}, \mathrm{Po}$ & $9 \mathrm{~d}$ & Yes (VB, Po) \\
\hline EV7 & $\mathrm{Co}, \mathrm{Hi}, \mathrm{Po}, \mathrm{MG}, \mathrm{APT}$ & $9 \mathrm{~d}$ & Yes (Po, APT, MG) \\
\hline EV6 & $\mathrm{Co}, \mathrm{Hi}, \mathrm{Po}, \mathrm{MG}, \mathrm{APT}, \mathrm{ZI}$ & $12 \mathrm{~d}$ & Yes (Po, APT, MG, SN) \\
\hline EV60 & $\mathrm{Co}, \mathrm{Hi}, \mathrm{LP}, \mathrm{Po}, \mathrm{MG}$ & $12 \mathrm{~d}$ & No \\
\hline EV49 & $\mathrm{Co}, \mathrm{Hi}, \mathrm{ZI}, \mathrm{SN}$ & $13 \mathrm{~d}$ & No \\
\hline EV81 & Co, Hi, LP, Po & $15 \mathrm{~d}$ & No \\
\hline EV65 & Co, Hi, LP, Po & $20 \mathrm{~d}$ & No \\
\hline EV66 & Co, Hi, LP, Po, MG & $20 \mathrm{~d}$ & No \\
\hline EV47 & Co, Hi, LP, Po, ZI & $20 \mathrm{~d}$ & No \\
\hline EV42 & $\mathrm{Co}, \mathrm{Hi}, \mathrm{VB}, \mathrm{ZI}$ & $21 \mathrm{~d}$ & No \\
\hline GC180 & $\mathrm{Co}, \mathrm{Hi}, \mathrm{LP}, \mathrm{MG}, \mathrm{ZI}$ & $30 \mathrm{~d}$ & No \\
\hline EV53 & $\mathrm{Co}, \mathrm{Hi}, \mathrm{LP}, \mathrm{Po}$ & $31 \mathrm{~d}$ & No \\
\hline EV82 & $\mathrm{Co}, \mathrm{Hi}, \mathrm{SC}$ & $32 \mathrm{~d}$ & No \\
\hline GC157 & Co, Hi, LP, Po, VB & $40 \mathrm{~d}$ & No \\
\hline EV36 & $\mathrm{Co}, \mathrm{Hi}, \mathrm{LP}$ & $42 \mathrm{~d}$ & No \\
\hline EV12 & $\mathrm{Co}, \mathrm{Hi}, \mathrm{SC}, \mathrm{MG}$ & $52 \mathrm{~d}$ & No \\
\hline EV11 & $\mathrm{Co}, \mathrm{Hi}, \mathrm{LG}, \mathrm{ZI}, \mathrm{SN}$ & $72 \mathrm{~d}$ & No \\
\hline EV27 & Co, Hi, LP, Po, ZI, SN & $120 \mathrm{~d}$ & No \\
\hline EV25 & Co, Hi, LP, Po, ZI, SN & $180 \mathrm{~d}$ & No \\
\hline EV26 & $\mathrm{Co}, \mathrm{Hi}, \mathrm{LP}, \mathrm{Po}, \mathrm{ZI}, \mathrm{SN}$ & $180 \mathrm{~d}$ & No \\
\hline
\end{tabular}

For abbreviations see Table 1.

chanical lesion (Figs. 1, 6). Larger numbers were present in the animals examined at shorter survival times with a peak in the one animal examined at $17 \mathrm{dpo}$ (Fig. $4 F, G$ ), which was also the only animal in which the graft impinged directly on the TRN. However, we made cell counts (Table 2) only in the animals examined with the AP probe, since with the radiolabeled probe it was not possible to distinguish clearly individual neurons with high GAP43 expression against the relatively high background level of GAP-43 expression present in all thalamic nuclei with the exception of TRN.

At early survival times, up to $13 \mathrm{dpo}$, the graft itself contained negligible levels of GAP-43 mRNA, but at longer survival times it was labeled as the Schwann cells progressively expressed higher levels of GAP-43 mRNA (Fig. $4 F, H, I$ ). As in the other experimental situations examined central glia did not appear to express detectable levels of GAP-43 mRNA.

\section{Expression of GAP-43 $m R N A$ in regenerating TRN neurons}

In two of the three rats used for this study, neurons retrogradely labeled with HRP were found in the T'RN ipsilateral to the graft. In these same animals, sections immediately adjacent to those processed for HRP histochemistry and processed for GAP-43 in situ hybridization, showed the presence of neurons expressing high levels of GAP-43 mRNA in the TRN ipsilateral to the graft. There was a very close correspondence between the pattern of retrograde labeling and the pattern of GAP-43 mRNA expression. As illustrated in Figure $7, A$ and $B$, a large number of neurons retrogradely labeled with CT-HRP/WGA-HRP was present in the dorsal part of the caudal TRN (Fig. 7B); in adjacent sections this part of the TRN also displayed heavy labeling for the presence of GAP-43 mRNA (Fig. 7A). By comparing immediately adjacent sections at higher magnification it was possible to establish that not only was the retrograde labeling coextensive with the in situ labeling but that many individual neurons in the TRN, were heavily labeled with both retrogradely transported HRP conjugate (Fig. 7C) and with silver grains, indicating the presence of GAP-43 mRNA (Fig. 7D). These observations establish unambiguously that increased GAP-43 mRNA expression occurs in neurons whose axons have regenerated along the peripheral nerve graft.

\section{Immunohistochemistry}

GAP-43 immunostaining in the thalamus of control adult rats

In the two normal adult rats examined the thalamus appeared diffusely $\mathrm{G} \Lambda \mathrm{P}-43$ immunopositive. In agreement with a previous report (Benowitz et al., 1988), based on data obtained with antibodies against GAP-43 different from the one used in the present study, immunostaining varied in intensity in the different nuclei; in particular there was only very weak staining in the TRN. At higher magnification the immunoproduct was associated with the neuropil and was granular in appearance. We found no evidence for cell body immunostaining in any part of the thalamus of normal control animals. 

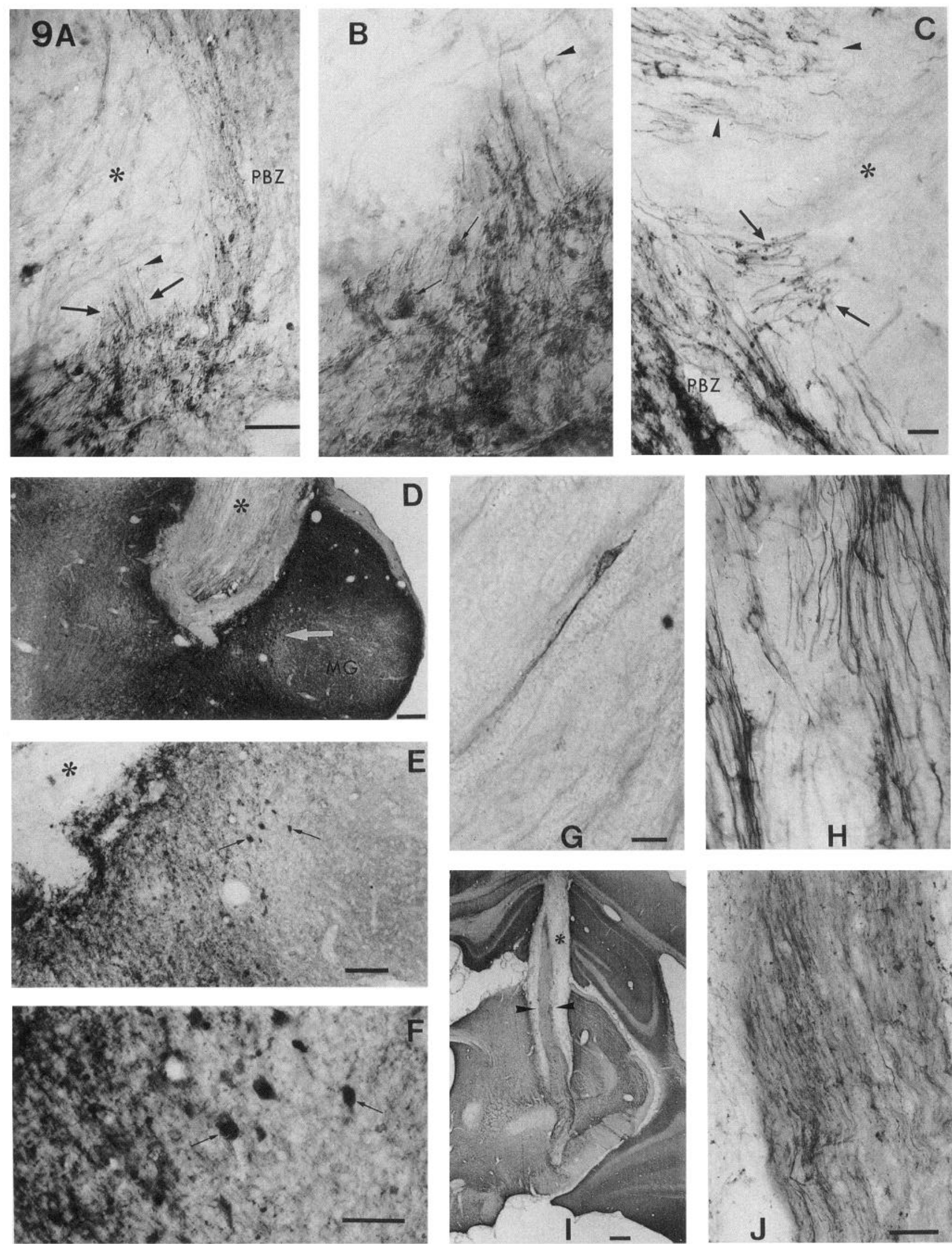

Figure 9. Photomicrographs of GAP-43 immunoreactive elements in the diencephalon close to and within peripheral nerve grafts $(*)$ at postgrafting survival times of $9 \mathrm{~d}(A-G), 30 \mathrm{~d}(H)$, and $180 \mathrm{~d}(I, J) . A-C$, Immunoreactive axons in the brain parenchymal border zone $(P B Z)$ around the tip of the graft and in places apparently streaming into it (arrows in $A$; higher magnification and a different level of focus shown in $B$ ). Note the 
GAP-43 immunostaining after stab wound lesion of the thalamus

We examined by light microscopy 15 animals which had received a single stab wound lesion in the left thalamus, with postoperative survival periods of 4-32 d (Table 3), and two animals by electron microscopy at 7 and $11 \mathrm{dpo}$.

Light microscopy. At survival times of 4-15 dpo a lesion 600$800 \mu \mathrm{m}$ in radius, with a central cavity surrounded by disorganized vacuolized tissue was apparent (Fig. $8 A-C, F$ ); this region was slightly more heavily immunostained than control tissue or the apparently normal neuropil around the lesion site (Fig. $8 A, B)$. In the single animal examined at 4 dpo, the immunoreaction was very weak, but showed the presence of a few, faintly GAP-43 immunopositive cell bodies (1-5 per section up to $200 \mu \mathrm{m}$ from the center of the lesion) located in the lesioned Po and APT. In addition in five out of the six animals examined at $7 \mathrm{dpo}$, and in one animal examined at $12 \mathrm{dpo}$, sparse, weakly GAP-43 positive cell bodies (Fig. $8 B, D, G$ ) (two to five per section, up to $100 \mu \mathrm{m}$ from the center of the lesion) and thin beaded fibers (Fig. 8E), which are very likely to represent axonal sprouts, were apparent immediately adjacent to the margins of the central cavity. The labeled cell bodies were located in the damaged Po, APT, and rarely in the LP and LG, in the MG (especially in its medial division), in the $\mathrm{VB}$, and in the zona incerta (ZI). However, labeled cell bodies were never found adjacent to lesions extending into the TRN.

The immunopositive cells were small, around $10 \mu \mathrm{m}$ in diameter, pyramidal to ovoid in shape and with uniform faint staining of the cytoplasm (Fig. $8 D, G$ ). Cells with a similar morphology or distribution were not found in adjacent sections immunostained for GFAP to reveal reactive astrocytes (data not shown), and we therefore consider these GAP-43 immunoreaclive cells to be neuronal, although in only very few cells did the immunoreactivity extend into the dendrites or axon (Fig. $8 G$ ).

We found no immunopositive cell bodies in the thalamus contralateral to the lesion, or in other brain areas either lesioned or intact. No cell body labeling was seen in control sections which had been incubated with blocking serum omitting the primary antibody, or containing, instead, normal mouse serum.

After survival times longer than $15 \mathrm{dpo}$, the lesion was inconspicuous and was seen either as a thin line of increased GAP43 immunoreactivity, or as a cyst (or a series of small cysts) surrounded by a zone of tissue with slightly increased GAP-43 immunoreactivity.

Electron microscopy. In all four animals (7, 11, and $12 \mathrm{dpo})$ reaction product was seen in small nonmyelinated axons and in some small myelinated axons (see Fig. 10A) close to the cystic area produced by the lesion and in some small astrocytic processes.

In the contralateral thalamus and in the ipsilateral thalamus distant from the lesion there was GAP-43 labeling of small numbers of nonmyelinated axons and small myelinated axons, and of a very few small dendritic and astrocytic processes. In the material processed with normal mouse serum instead of primary GAP-43 antibody, a few small astrocyte processes contained reaction product, suggesting that some astrocyte processes had labeled with the secondary antibody. However, sections processed with phosphate-buffered saline in place of the primary antibody showed no staining of any elements, suggesting that the normal mouse serum stained some astrocyte processes.

\section{GAP-43 immunostaining after implantation of a peripheral nerve segment in the thalamus}

We examined by light microscopy 26 rats which had a segment of tibial nerve implanted in the left thalamus and which.had survived between 7 and 180 dpo (Table 4), and 6 rats by electron microscopy at survival times between 7 and $21 \mathrm{dpo}$.

Light microscopy. The effect of implanting a peripheral nerve graft into the thalamus was to induce a more intense and prolonged increase in GAP-43 immunoreactivity than that observed after simple mechanical lesion.

Between 7 and 21 dpo increased levels of GAP-43 neuropil immunostaining were observed at the interface between brain and graft and to a lesser extent in the thalamic neuropil adjacent to the graft tip and up to a distance of $200-300 \mu \mathrm{m}$ from the graft border. A few GAP-43 positive sprouts were found at the brain-graft interface at 7 dpo (six animals), and in much larger numbers at 9 dpo (two animals) (Fig. 9A-G). The sprouts were beaded and followed a tortuous pathway, some penetrating the graft directly (Fig. $9 A-C$ ), whereas others remained at its periphery, and were occasionally observed to reverse direction at the brain-graft interface. Many sprouts were found deep within the graft at 9 dpo (arrowheads, Fig. 9C) including some immunoreactive growth cone-like structures (Fig. 9G). Sprouts were still present at the brain-graft interface at 12-20 dpo (six animals) but in smaller numbers, and were no longer visible at 21 dpo. Over the same period, an increasing number of GAP43 positive axons was found inside the graft itself; however, due to the increasing immunostaining of Schwann cells in the graft (see EM results and Fig. 11A-C), at survival times longer than 15 dpo it became extremely difficult to identify the immunopositive axons by light microscopy.

GAP-43 positive perikarya were found in the thalamus close to the graft tip and at the brain-graft interface in both animals examined at 9 dpo (Figs. $9 B, 10 D-F$ ) and, to a lesser extent at 12 dpo in one animal of two. In contrast to what was seen after stab wound we did not find evidence for GAP-43 immunopositive perikarya in any of the six animals examined at 7 dpo.

In one of the two 9 dpo animals the graft tip ended in the region of caudal thalamus between $L P, V B, P o$, and TRN and

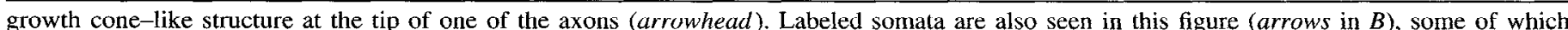

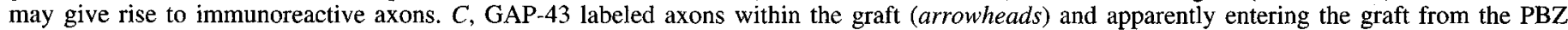

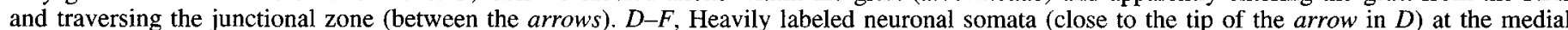

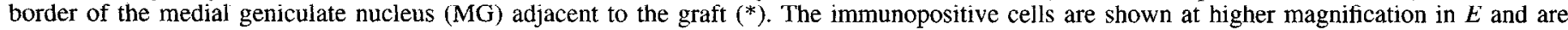

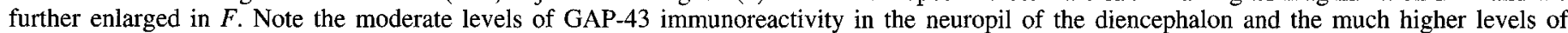

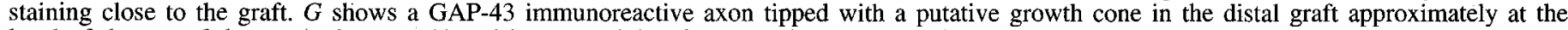

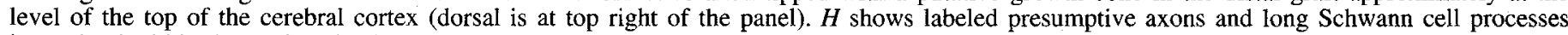

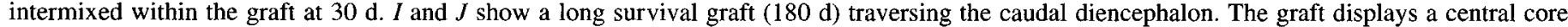

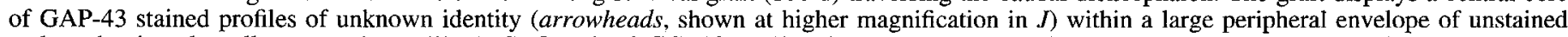

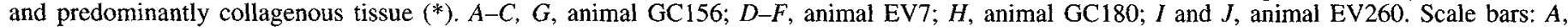
$100 \mu \mathrm{m} ; C, 20 \mu \mathrm{m}$ for $B, C$, and $H ; D, 200 \mu \mathrm{m} ; E, 100 \mu \mathrm{m} ; F, 50 \mu \mathrm{m} ; G, 10 \mu \mathrm{m} ; I, 450 \mu \mathrm{m} ; J, 50 \mu \mathrm{m}$. 

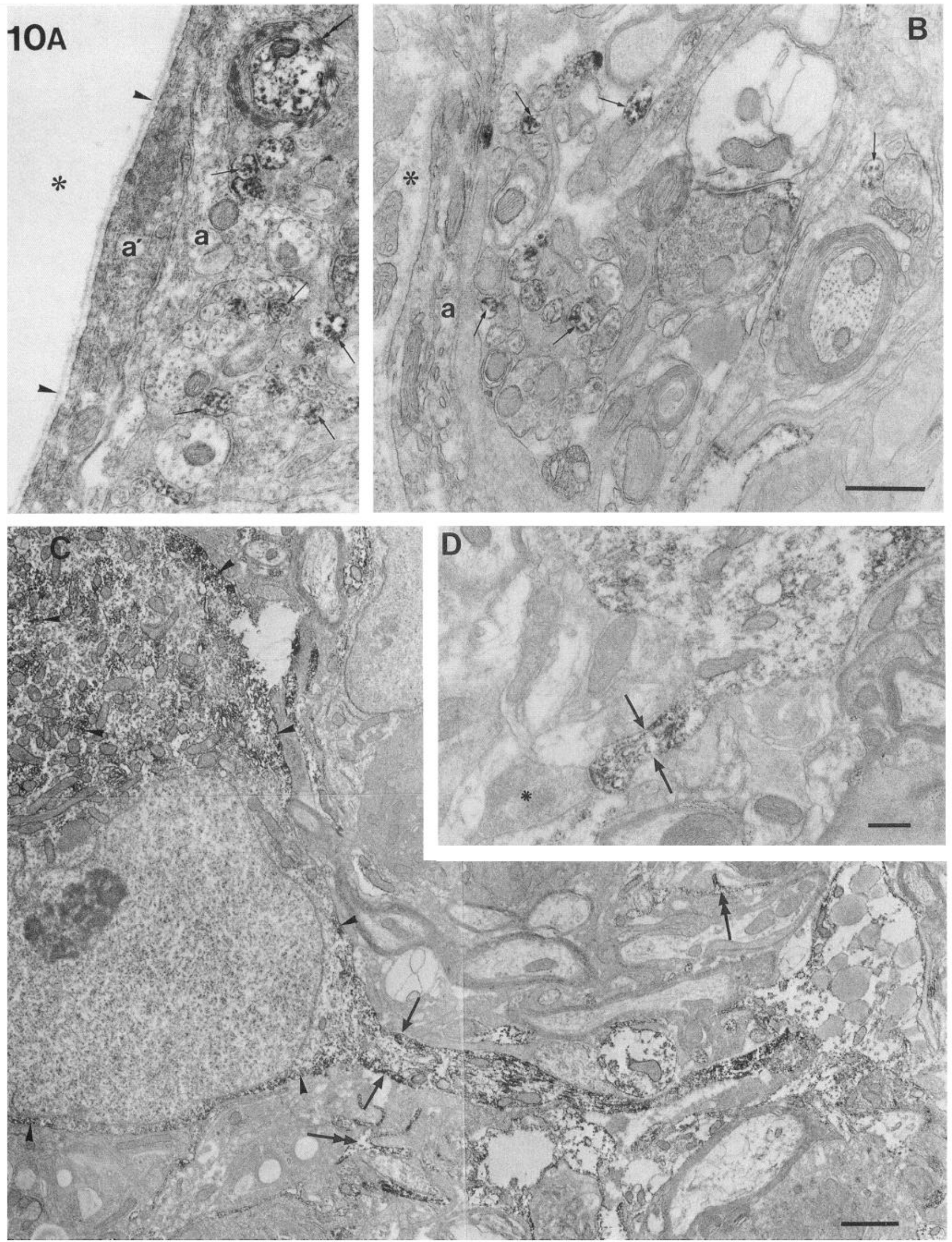

Figure 10. Electron micrographs of GAP-43 immunoreactive neural elements in the superior colliculus adjacent to a stab wound $7 \mathrm{~d}$ after injury $(A)$ and in the medial geniculate nucleus close to a graft $11 \mathrm{~d}$ after implantation $(B-D)$. In $A$ numerous immunoreactive axon sprouts (some of which are arrowed) and a small myelinated axon (double arrow) are clustered among astrocyte processes $(a)$ one of which $\left(a^{\prime}\right)$ is coated with 
the immunopositive neurons (2-10 per section) were concentrated at the brain-graft interface and in VB and $P o$ up to a distance of 200-300 $\mu \mathrm{m}$ from the graft tip (Fig. 9B). In the other 9 dpo animal the graft tip was located in the most caudal thalamus, between Po and the medial division of $\mathrm{MG}$, and at the border with APT, and GAP-43 positive neurons were present in larger numbers (up to 40 cells per section) and spread over a wider area (up to $1 \mathrm{~mm}$ from the graft tip) (Fig. 9D-F). The immunopositive cells were concentrated ventral and lateral to the graft, in Po, APT, and the medial division of MG, as was also seen following stab wound lesions of this region. However, in the presence of a graft the neuronal perikarya were more numerous, more densely immunostained, and spread over a much larger area (see above) than after stab wounds. In addition while the immunopositive neurons found in these areas after stab wounds had a diameter of around $10 \mu \mathrm{m}$, the immunopositive neurons seen in the same areas, but adjacent to a graft, werc larger, with diameters of 15-20 $\mu \mathrm{m}$. As was the case in one of the 9 dpo animals, in the 12 dpo animal which showed GAP-43 immunopositive perikarya adjacent to the graft, the graft tip was in the most caudal thalamus. However, in the 12 dpo animal the immunopositive cells were present in much smaller numbers (14 per section) than in the 9 dpo animal, and in addition to being present in Po, APT, and in the medial division of MG, were also found in the substantia nigra (SN) (see Table 4).

At survival times longer than 21 dpo, in all animals examined the GAP-43 immunoreactivity of the thalamus had returned to control levels, and immunopositive cell bodies or sprouts were not apparent. In the animals examined between 21 dpo and 72 $d p o$ the graft appeared densely and diffusely labeled with immunopositive axon and Schwann cell-like processes (Fig. 9H). In the two animals examined $180 \mathrm{dpo}$ the graft appeared to have lost some of its immunoreactivity. The loss appeared to progress from the periphery towards the center of the graft, in parallel with the deposition of progressively larger amounts of collagen (Fig. 9I). In the central part of the graft, especially in its distal part, there were a few very thin and elongate immunopositive processes which we were unable to identify with confidence as either axons or thin Schwann cell processes (Fig. 9J).

Electron microscopy. At 7 dpo ( $n=1$; not illustrated) GAP43 staining was seen within a few reactive neurites, small nonmyelinated and small myelinated axons, axon terminals, and some fine astrocyte processes. In the graft, small numbers of axons both within Schwann cell columns and outside them were immunopositive. Also labeled were large putative growth cone profiles filled with clear vesicles of varying size. These tended to lie outside or at the periphery of Schwann cell columns, either adjacent to narrow fibroblast processes and endoneurial collagen or pressed against the outer membrane of Schwann cell processes. Other large nonmyelinated immunoreactive profiles, containing lysosome-like electron dense bodies, may have been degenerating. No Schwann cell processes were labeled at this stage.
At postgrafting survival times of 11 and $12 d p o(n=3)$ (Figs. $10 B-D, 11 E, F)$ GAP-43 reaction product was evident in many profiles in the thalamic parenchyma immediately adjacent to the graft, predominantly in small to medium-sized nonmyelinated axons, where it tended to be diffusely spread throughout the cytoplasm or was present in patches often associated with microtubules and the outer mitochondrial membrane (Fig. 10B). Some vesicle-filled axon terminals were also labeled as were a few small myelinated axons. Some reaction product was also seen in neuronal somata (Fig. 10C) and in dendrites of different dimensions (Fig. 10D) where it was either concentrated in small dense patches or was more diffusely spread throughout the cytoplasm. Many small astrocyte processes were also labeled, particularly very narrow sheet or finger-like processes (Fig. $11 E, F$ ). Medium-sized astrocyte processes were lightly labeled (Fig. $11 E$ ), often throughout their cytoplasm, and sometimes had concentrations of dense reaction product in a thin rim under the plasma membrane. Sometimes reaction product was patchily distributed especially in the largest astrocyte processes and cell bodies. Astrocytes of the glia limitans at the graft-brain interface and around blood vessels (Fig. $11 F$ ) were labeled in this way as were astrocytes which often partially enwrapped neuronal elements beneath the glia limitans.

In the graft small to medium-sized nonmyelinated axons both inside and outside Schwann cell columns (no myelinated axons were present within the graft at this survival time) were labeled in a similar manner to axons within the brain, although some were labeled relatively homogeneously throughout their cytoplasm. A few putative Schwann cell processes were also labeled. Such labeling was not common and involved only long narrow Schwann cell processes, which tended to have diffuse label throughout and intermittent patches of heavier reaction product. A few, very fine, long fibroblast-like processes lacking a basal lamina were also lightly immunoreactive.

At 21 dpo $(n=2)$ (Fig. $11 A-D)$ the GAP-43 labeling within the thalamic tissue abutting the graft was essentially similar to that at 11 dpo. Small and medium-sized nonmyelinated axons and some small dendritic and astrocytic processes were labeled Many of the narrow astrocyte lamellae contributing to the glia limitans, which is extensive and more complex at this postoperative stage (see Campbell et al., 1992a), were labeled. In contrast the GAP-43 labeling of the graft was substantially different from that seen at 11-12 dpo because large numbers of Schwann cell processes were now immunopositive. (Fig. $11 A-C$ ). Often entire processes, including some large ones, were filled with reaction product (Fig. $11 B, C$ ) and reaction product was also present in the perinuclear cytoplasm of many Schwann cells (Fig. 11A). Fine, long, heavily immunostained Schwann cell processes often arising from larger more lightly immunostained processes were common within the Schwann cell columns (Fig. $11 B, C)$. The narrow processes were generally labeled throughout their length. In many of the medium to large Schwann cell processes reaction product was concentrated in a rim under the plas-

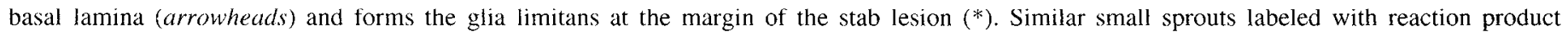

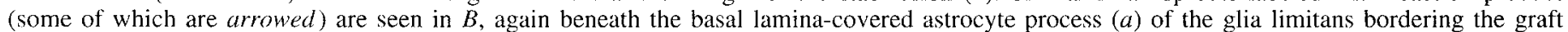

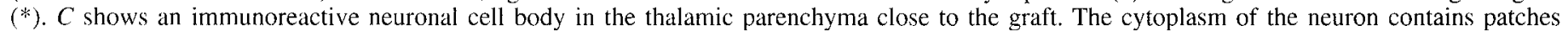

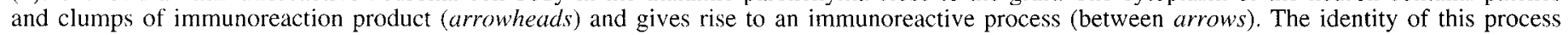

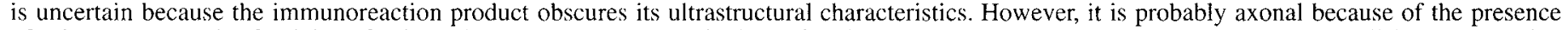

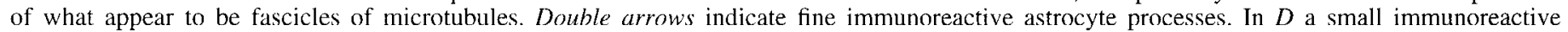

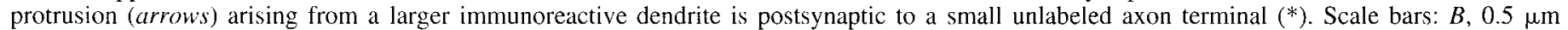
for $A$ and $B ; C, 1.0 \mu \mathrm{m} ; D, 0.5 \mu \mathrm{m}$. 

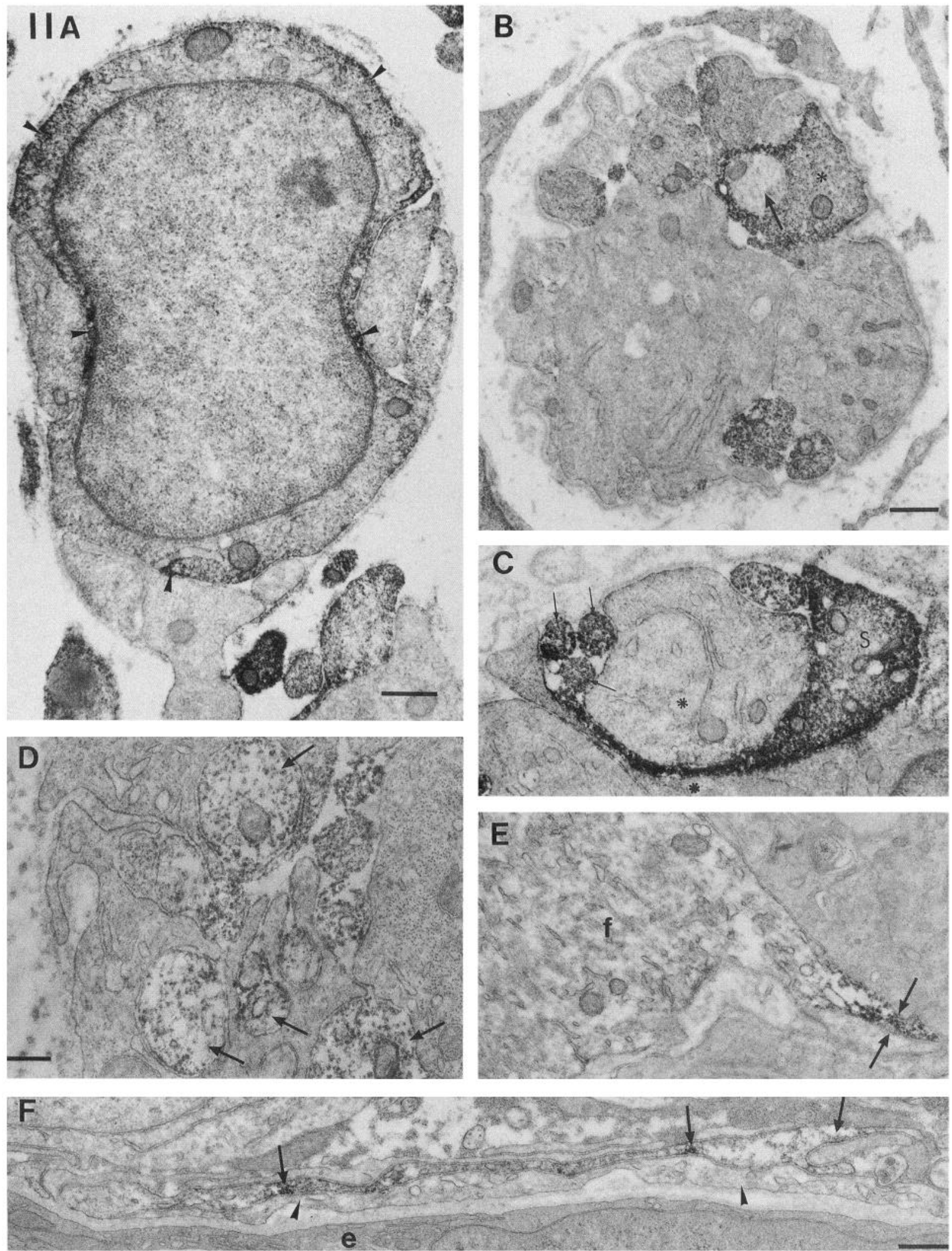

Figure 11. GAP-43 immunoreactive neural elements in the graft $21 \mathrm{~d}$ after implantation $(A-D)$ and in the medial geniculate nucleus close to the graft $11 \mathrm{~d}$ after implantation $(E, F)$. In $A$ an immunoreactive Schwann cell displays patches of cytoplasmic reaction product (arrowheads). In $B$ a Schwann cell column containing several immunoreactive profiles one of which is a Schwann cell process $(*)$ enwrapping an apparently unlabeled axon-like process (arrow). In $C$, another immunoreactive Schwann cell process $(S)$ gives rise to a heavily labeled fine extension sandwiched between two apparently unlabeled Schwann cell processes $(*)$. Close by are three immunoreactive axon-like profiles (arrows). In another Schwann cell column, illustrated in $D$, the immunoreactive structures (some of which are arrowed) seem all to be axons and the Schwann cell processes appear 
nia membrane (Fig. 11C). Many small and medium-size nonmyelinated axons were labeled homogeneously with reaction product (Fig. 11C,D). The majority of axons were in Schwann cells columns but some labeled axons were outside Schwann cell columns dispersed amongst collagen fibers. Some putative astrocyte processes in the graft were also labeled.

\section{Discussion}

We show that (1) mechanical injury to the thalamus of the adult rat is a sufficient stimulus to elicit a modest and transient upregulation of GAP-43 expression in thalamic neurons ipsilateral to the lesion; (2) thalamic neurons with an established propensity to regenerate axons along peripheral nerve grafts, such as those of the TRN (Benfey et al., 1985; Morrow et al., 1993) and the region of and around the medial division of the MG (Morrow et al., 1993), have a high capacity to upregulate GAP-43 after such a lesion; (3) after peripheral nerve implantation into the thalamus, the injury-induced GAP-43 response of TRN and other thalamic neurons is both enhanced and prolonged; (4) the neurons which express high levels of GAP-43 mRNA under these conditions are (at least predominantly) those that have axons regenerating along the grafts; (5) Schwann cells in the grafts and astrocytes of the thalamic parenchyma and of the glia limitans around the graft become GAP-43 immunopositive after graft implantation, although GAP-43 mRNA is detectable only in neurons and in graft Schwann cells.

GAP-43mRNA and protein upregulation after simple lesion in the thalamus is short lasting (4-12 dpo), and might parallel an abortive sprouting response. Increased GAP-43 immunoreactivity has been described in other CNS regions after lesion (Ostreicher et al., 1988; Benowitz et al., 1990), and has been associated with reactive synaptogenesis. In our experimental situation it is difficult to determine beyond doubt if the neurons with high levels of expression of GAP-43 are indeed axotomized neurons undergoing abortive regeneration or are intact neurons undergoing collateral or terminal sprouting. However, in favor of an upregulation restricted to lesioned neurons is the finding that GAP-43 positive neuronal cell bodies are mainly concentrated near the center of the lesion, and not at its periphery, suggesting that they belong to neurons axotomized close to the cell body, or in the portion of the TRN known to project to the injured area (Ohara and I ieherman, 1985; Mitrofanis and Guillery, 1993), with larger numbers labeled in the case of a direct lesion of the TRN, when axonal damage is maximal.

Thalamic neurons appear to differ in their capacity to upregulate GAP-43 after lesion, suggesting that the molecular responses to injury and possibly the regenerative potential of different populations of thalamic neurons may be intrinsically different (Fawcett, 1992). On the other hand after lesion of the CNS parenchyma there is local production of growth factors (Nieto-Sampedro et al., 1982), including NGF, by neurons, astrocytes (Lu et al., 1991), and possibly other cells migrating from leaky parenchymal blood vessels, which peaks around 7 dpo and decreases progressively thereafter. Thus growth factors might influence GAP-43 expression in lesioned thalamic neurons. In fact NGF can influcnce the phosphorylation and the intracellular localization of GAP-43 (van Hoff et al., 1989; Meiri and Burdick, 1991) as well as expression of the GAP-43 gene (Federoff et al., 1988). Moreover it has been shown in PC12 cells that GAP-43 antisense oligonucleotides can block NGF induced neurite outgrowth (Jap et al., 1992), and that transfection of the human GAP-43 gene into PC12 cells enhances the action of NGF on neurite formation and elongation (Yankner et al., 1990). Thus, neurons able to massively upregulate GAP-43 expression as a response to injury, might be more able to respond to NGF, or other growth factors, and stand a better chance of regencrating. However, the ncurotrophic requirements of thalamic neurons, including TRN, are unknown.

The GAP-43 response elicited by the presence of a nerve graft is qualitatively and quantitatively much stronger than after stab wounds in terms of duration, extent of neuronal cell body labeling, and numbers of GAP-43 positive sprouts. A possible explanation for these differences could be that the lesion made by graft insertion is substantially larger than a stab wound lesion and/or that the presence of the graft results in a continuous compressive action on the thalamic parenchyma. However, when a frozen killed graft (which does not support CNS axon regeneration) is implanted in the thalamus, the GAP-43 response is closer in intensity to that observed after stab wound lesion than to the response following implantation of a living nerve graft (Vaudano et al., 1992b). Thus, thalamic neurons appear to be able to respond to a factor or factors produced by Schwann cells, such as growth factors (including NGF, BDNF and CNTF (Heumann et al., 1987; Meyer et al., 1992; Sendtner et al., 1992) or present on the surface of the Schwann cells such as cell adhesion mol ecules (Daniloff et al., 1986) and this factor (or factors) enhances and prolongs their injury-induced GAP-43 response.

Neurons which show upregulation of GAP-43 mRNA in the presence of a living peripheral nerve graft belong to the same thalamic nuclei (TRN and MG) whose neurons have a high capacity to regenerate their axons along such a growth permissive substrate (Benfey et al., 1985; Morrow et al., 1993) suggesting that the capacity to express high levels of GAP-43 might correlate with axonal growth potential. This correlation is enormously strengthened by our finding that retrograde cell body labeling from the distal graft and high levels of GAP-43 expression are coextensive in the TRN and that many of the neurons in such regions of TRN are unequivocally doubled labeled. Previous studies suggested a correlation between successful axonal regeneration and GAP-43 upregulation (Campbell et al., 1991; Doster et al., 1991; Tetzlaff et al., 1991), but our findings provide the strongest evidence so far available that GAP-43 upregulation predisposes to, is closely correlated with, and may be necessary for, successful CNS axonal regeneration into peripheral nerve grafts.

Both after lesion and after peripheral nerve grafting the number and distribution of GAP-43 immunopositive neurons was much more restricted than that of neurons expressing high levels of GAP-43 mRNA. Immunopositive neurons were found only in the immediate vicinity of the mechanical lesion or of the graft tip (and in some regions of the caudal thalamus), and not in the TRN, despite the massive GAP 43 mRN 1 upregulation observed by in situ hybridization in these same neurons. A possible

$\leftarrow$

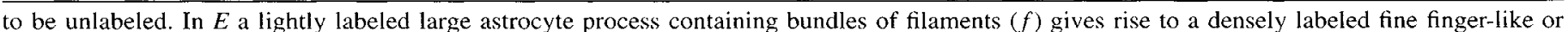

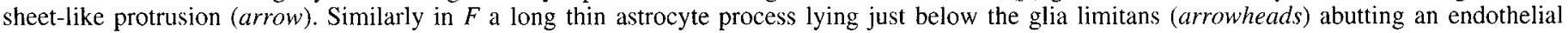
cell $(e)$ of a small blood vessel, contains patches of reaction product (e.g., at arrows). Scale bars: $A-C, E$, and $F, 0.5 \mu m ; D, 0.2 \mu m$. 
explanation of this discrepancy is that neurons of different thalamic nuclei export newly synthesized GAP-43 protein along their axons with different efficiencies, so that only in some neurons does perikaryal GAP-43 content reach immunohistochemically detectable levels. It is also possible that the immunopositive perikarya belong to dying neurons which have lost the capacity to export the protein. However, the fact that the immunopositive neurons were located in the same nuclei which contained neurons with high expression of GAP-43 mRNA, and that they were present in larger numbers after grafting than after simple lesion argues strongly against this possibility. We also cannot rule out completely the possibility that GAP-43 message is not translated into protein under all conditions and in all neurons; this would imply that GAP-43 levels are controlled by several factors acting at transcriptional, translational and posttranslational levels.

After stab wound Icsion GAP-43 immunopositive neuronal cell bodies and neurons expressing high levels of GAP-43 mRNA were found at around the same short survival times (412 dpo), whereas after peripheral nerve grafting neurons containing GAP-43 mRNA were found up to 30 dpo and possibly beyond (not examined), although immunopositive perikarya were visualized only between 9 and 12 dpo. Such a result agrees with observations that immunohistuchemically detectable levels of GAP-43 protein are found only in cell bodies of neurons growing in vitro at short intervals after plating, before they start to elaborate neurites at which time the protein is exported along the neurites and becomes undetectable in the perikaryon (Meiri et al., 1988).

In our experimental situation we found GAP-43 not only in neurons but also in peripheral and central glia. In Schwann cells, GAP-43 immunoproduct was first observed at 10-12 dpo with a peak at $1 \cdots 2$ months after graft insertion; later GAP-43 immunoreactivity in Schwann cells decreased in a similar manner to that observed by Curtis et al. (1992) in distal stumps of chronically denervated cut peripheral nerves. GAP-43 reaction product was particularly dense in the narrowest and thinnest Schwann cell processes, that is, in those areas likely to undergo the most rapid changes of shape, suggesting an involvement of GAP-43 in the remodeling of fine Schwann cells processes. In fact Schwann cells expressing high levels of GAP-43 mRNA and GAP-43 immunoreactivity and with a very complex morphology, are found in denervated motor endplates; when reinnervation occurs the elaborate processes and the GAP-43 expression are both lost (Woolf et al., 1992). In the longest surviving grafts (6 months) GAP-43 immunoreactivity of Schwann cells was much lower than in shorter survival grafts. In such long-term grafts there is fibrosis with collagen accumulation and a reduction in Schwann cell number; we agree with Curtis et al. (1992) that GAP-43 expression in Schwann cells does not depend only on axonal signals but also on other variables such as cell density. GAP-43 immunoproduct was also visualized in small and narrow astrocytic processes, but astrocytes were not found to contain detectable amounts of GAP-43 mRNA. GAP-43 immunoreactivity has been described in astrocytes in vitro (Vitkovic ct al., 1988), but not in quiescent or reactive astrocytes in vivo (Curtis et al., 1991). Such a discrepancy with our result may be due to the fact that Curtis et al. (1991) examined their material with immunofluorescence and at light microscope level only, whereas we used the more sensitive avidin-biotin-peroxidase method for immunostaining and examined our material at the electron microscopic level. The fact that we did not find cvidence for expression at detectable levels of GAP-43 mRNA in astrocytes might demonstrate its low levels in such cells or might indicate that the GAP-43 protein detected in the astrocytic processes had been taken up from neurons.

In conclusion we demonstrated that certain thalamic neurons upregulate GAP-43 protein and mRNA as a response to mechanical injury, and that thalamic neurons can respond to the presence of a peripheral nerve autograft by enhancing and prolonging their GAP-43 response. The thalamic neurons which show the greatest upregulation of GAP-43 mRNA and protein in response to mechanical injury and peripheral nerve implantation correspond to those populations of thalamic neurons (TRN and a region adjacent to the MG nucleus) which show the greatest propensity to regenerate their axons along such peripheral nerve grafts (Benfey et al., 1985; Morrow et al., 1993), and indeed some of the TRN neurons displaying high levels of GAP43 mRNA have axons that have regenerated over long distances into the graft. These findings strongly suggest a specific role for GAP-43 in the regenerative axonal growth of injured CNS neurons.

\section{References}

Aguayo AJ (1985) Axonal regeneration from injured neurons in the adult mammalian central nervous system. In: Synaptic plasticity (Cotman CW, ed), pp 457-484. New York: Guilford.

Baetge EE, Hammang JP (1991) Neurite outgrowth in PC12 cells deficient in GAP-43. Neuron 6:21-30.

Basi GS, Jacobson RD, Virag I, Schilling J, Skene JH (1987) Primary structure and transcriptional regulation of GAP-43, a protein associated with nerve growth. Cell 49:785-791.

Benfey M, Bunger UR, Vidal-Sanz M, Bray GM, Aguayo AJ (1985) Axonal regeneration from gabaergic neurons in the adult rat thalamus. J Neurocytol 14:279-296.

Benowitz LI, Apostolides PJ, Perrone-Bizzozero N, Finkelstein SP, Zwiers $H$ (1988) Anatomical distribution of the growth associated protein GAP-43/B-50 in the adult rat brain. J Neurosci 8:339-352.

Benowitz LI, Rodriguez WR, Neve RL (1990) The pattern of GAP-43 immunostaining changes in the rat hippocampal formation during reactive synaptogenesis. Mol Brain Res 8:17-23.

Campbell G, Anderson PN, Turmaine M, Lieberman AR (1991) GAP43 in the axons of mammalian CNS neurons regenerating into peripheral nerve grafts. Exp Brain Res 87:67-74.

Campbell G, Lieberman AR, Anderson PN, Turmaine M (1992a) Regeneration of adult rat CNS axons into peripheral nerve autografts: ultrastructural studies of the early stages of axonal sprouting and regenerative axonal growth. J Ncurocytol 21:755-787.

Campbell G, Vaudano E, Davies AP, Anderson PN, Lieberman AR Schreyer DJ (1992b) GAP-43 and NGF-receptor expression in adult rat thalamus after injury or peripheral nerve implantation. Soc Neurosci Abstr 18:425.

Chong MS, Fitzgerald M, Winter J, Hu-Tsai M, Emson PC, Wiese U, Woolf C (1992) Gap-43 mRNA in rat spinal cord and dorsal root ganglia neurons: developmental changes and re-expression following peripheral nerve injury. Eur J Neurosci 4:883-895.

Curtis R, Hardy R, Reynolds R, Spruce BA, Wilkin GP (1991) Down regulation of GAP43 during oligodendrocyte development and lack of expression by astrocytes in vivo: implication for macroglial differentiation. Eur J Neurosci 3:876-886.

Curtis R, Stewart HJS, Hall SM, Wilkin GP, Mirsky R, Jessen KR (1992) GAP-43 is expressed by nonmyclin-forming Schwann cells of the peripheral nervous system. J Cell Biol 116:1455-1464.

Daniloff JK, Levi G, Grumet M, Reiger F, Edelman GM (1986) Altered expression of neuronal cell adhesion molecules induced by nerve injury and repair. J Cell Biol 103:929-945.

Doster SK, Lozano AM, Aguayo AJ, Willard MB (1991) Expression of the growth associated protein GAP-43 in adult rat retinal ganglion cells following axonal injury. Neuron 6:635-647.

Fawcett JW (1992) Intrinsic neuronal determinants of regeneration. Trends Neurosci 15:5-8

Federoff HJ, Grabczyk E, Fishman MC (1988) Dual regulation of 
GAP-43 gene expression by nerve growth factor and glucocorticoids. J Biol Chem 263:19290-19295.

Heumann R, Korsching S, Bandtlow C, Thoenen H (1987) Changes in Nerve Growth Factor synthesis in non neuronal cells in response to sciatic nerve transection. J Cell Biol 104:1623-1631.

Hoffman PN (1989) Expression of GAP-43, a rapidly transported growth-associated protein, and class II beta tubulin, a slowly transported cytoskeletal protein, are coordinated in regenerating neurons. J Neurosci 9:893-897.

Jap TSE, Schmidt MM, Oestreicher AB, Gispen WH, Schotman P (1992) Inhibition of nerve growth factor-induced B-50/GAP-43 expression by antisense oligomers interferes with neurite outgrowth of PC12 cells. Biochem Biophys Res Commun 187:839-846.

Kruger L, Bendotti C, Rivolta R, Samanin R (1993) Distribution of GAP-43 mRNA in the adult rat brain. J Comp Neurol 333:417-434.

Lu B, Yokoyama M, Dreyfus CF, Black I (1991) NGF gene expression in actively growing brain glia. $\mathbf{J}$ Neurosci 11:318-326.

Meiri KF, Willard M, Johnson MI (1988) Distribution and phosphorylation of the growth associated protein GAP-43 in regenerating sympathetic neurons in culture. J Neurosci 8:2571-2581.

Meiri KM, Burdick D (1991) Nerve growth factor stimulation of GAP43 phosphorylation in intact isolated growth cones. J Neurosci 11: 31553164.

Meyer M, Matsuoka I, Wetmore C, Olson L, Thoenen H (1992) Enhanced synthesis of brain-derived neurotrophic factor in the lesioned peripheral nerve: different mechanisms are responsible for the regulation of BDNF and NGF mRNA. J Cell Biol 119:45-54.

Mitrofanis J, Guillery RW (1993) New views of the thalamic reticular nucleus in the adult and the developing brain. Trends Neurosci 16: 240-245.

Morrow DR, Campbell G, Lieberman AR, Anderson PN (1993) Differential regenerative growth of CNS axons into tibial and peroneal nerve grafts in the thalamus of adult rats. Exp Neurol 120:60-69.

Neve RL, Perrone BN, Finklestein S, Zwiers H, Bird E, Kurnil DM, Benowitz LI (1987) The neuronal growth-associated protein GAP43 (B-50, F1): neuronal specificity, developmental regulation and regional distribution of the human and rat mRNAs. Brain Res 388: 177-183.

Nieto-Sampedro M, Lewis ER, Cotman CW, Manthorpe M, Skaper SD, Barbin G, Longo FM, Varon S (1982) Brain injury causes a time dependent increase in neurotrophic activity at the lesion site. Science 217:860 861 .

Ohara PT, Lieberman AR (1985) The thalamic reticular nucleus of the adult rat: experimental anatomical studies. J Neurocytol 14:365-411.

Ostreicher AB, Devay P, Isaacson RL, Gispen WH (1988) Changes in the distribution of the neuron specific B-50, neurofilament protein and glial fibrillary acidic proteins following an unilateral mesencephalic lesion in the rat. Brain Res Bull 21:713-722.

Paxinos G, Watson C (1986) The rat brain in stereotaxic coordinates. Sydney: Ácademic.

Schreyer DJ, Skene JHP (1991) Fate of GAP43 in ascending spinal axons of DRG neurons after peripheral nerve injury: delayed accu- mulation and correlation with regenerative potential. J Neurosci 11: 3738-3751.

Sendtner M, Stöckli A, Thoenen H (1992) Synthesis and localization of ciliary ncurotrophic factor in the sciatic nerve of the adult rat after lesion and during regeneration. J Cell Biol 118:139-148.

Shea TB, Perrone-Bizzozzero NI, Beermann ML, Benowitz LI (1991) Phospholipid-mediated delivery of anti-GAP-43 antibodies into neuroblastoma cells prevents neuritogenesis. J Neurosci 11:1685-1690.

Skene JHP (1984) Growth associated proteins and the curious dichotomies of nerve regeneration. Cell 37:697-700.

Skene JHP, Willard M (1981a) Changes in axonally transported proteins during axon regeneration in toad retinal ganglion cells. J Cell Biol 89:86-95.

Skene JHP, Willard M (1981b) Axonally transported proteins associated with axon growth in rabbit central and peripheral nervous systems. J Cell Biol 89:96-103.

Tetzlaff W, Alexander SW, Miller FD, Bisby MA (1991) Response of facial and rubrospinal neurons to axotomy: changes in mRNA expression for cytoskeletal proteins and GAP-43. J Neurosci 11:25282544.

van Hoff COM, Holthius JCM, Ostreicher AB, Boonstra J, DeGraan PNE, Gispen WH (1989) Nerve growth factor induced changes in the intracellular localization of the protein kinase C substrate B50 in pheochromocytoma PC12 cells. J Cell Biol 108:1115-1125.

Vaudano E, Campbell G, Anderson PN, Schreyer DJ, Lieberman AR (1992a) Elevated Gap-43 levels in neurons close to stab wounds in adult rat brain. J Anat (Lond) 180:359-360.

Vaudano E, Campbell G, Anderson PN, Davies AP Schreyer DJ, Lieberman AR (1992b) GAP-43 in adult rat thalamus following stab wounds or the implantation of living or dead nerve autografts. Neurosci Lett S42:S18.

Vaudano, E, Campbell G, Lieberman AR (1993a) Injury reactions and axonal regeneration in the thalamus of the adult rat. In: Thalamic networks for relay and modulation (Minciacchi D, Molinari M, Macchi G, Jones EG, eds), pp 347-355. Oxford: Pergamon.

Vaudano E, Woolhead C, Campbell G, Anderson PN, Emson P, Lieberman AR (1993b) Upregulation of GAP-43 mRNA in adult rat thalamic and cerebellar neurons after lesion or peripheral nerve grafting. Eur J Neurosci [Suppl] 6:121.

Vitkovic L, Steisslinger HW, Aloyo VJ, Mersel M (1988) The 43-kDa neuronal growth-associated protein (GAP-43) is present in plasma membranes of rat astrocytes. Proc Natl Acad Sci USA 85:8296-8300.

Woolf C, Reynolds ML, Chong MS, Emson P, Irwin N, Benowitz I (1992) Denervation of the motor endplate results in the rapid expression by terminal Schwann cells of the growth associated protein GAP-43. J Neurosci 12:3999-4010.

Yankner BA, Benowitz LI, Villa KL, Neve RL (1990) Transfection of PC12 cells with the human GAP-43 gene: effects on neurite outgrowth and regeneration. Mol Brain Res 7:39-44.

Yao GL, Kiyama H, Tohyama M (1993) Distribution of GAP-43 (B50/ F1) in the adult rat brain by in situ hybridization using an alkaline phosphatase labeled probe. Mol Brain Res 18:1-16

Zuber MX, Goodman DW, Karns LR, Fishman MC (1989) The neuronal growth-associated protein GAP-43 induces filopodia in nonneuronal cells. Science 244:1193-1195. 